\title{
The importance of crown dimensions to improve tropical tree biomass estimates
}

\author{
Rosa C. Goodman, ${ }^{1}$ Oliver L. Phillips, and Timothy R. Baker \\ School of Geography, University of Leeds, Leeds LS29JT United Kingdom
}

\begin{abstract}
Tropical forests play a vital role in the global carbon cycle, but the amount of carbon they contain and its spatial distribution remain uncertain. Recent studies suggest that once tree height is accounted for in biomass calculations, in addition to diameter and wood density, carbon stock estimates are reduced in many areas. However, it is possible that larger crown sizes might offset the reduction in biomass estimates in some forests where tree heights are lower because even comparatively short trees develop large, well-lit crowns in or above the forest canopy. While current allometric models and theory focus on diameter, wood density, and height, the influence of crown size and structure has not been well studied.

To test the extent to which accounting for crown parameters can improve biomass estimates, we harvested and weighed 51 trees (11-169 cm diameter) in southwestern Amazonia where no direct biomass measurements have been made. The trees in our study had nearly half of total aboveground biomass in the branches $(44 \% \pm 2 \%$ [mean $\pm \mathrm{SE}$ ]), demonstrating the importance of accounting for tree crowns. Consistent with our predictions, key pantropical equations that include height, but do not account for crown dimensions, underestimated the sum total biomass of all 51 trees by $11 \%$ to $14 \%$, primarily due to substantial underestimates of many of the largest trees.

In our models, including crown radius greatly improves performance and reduces error, especially for the largest trees. In addition, over the full data set, crown radius explained more variation in aboveground biomass (10.5\%) than height (6.0\%). Crown form is also important: Trees with a monopodial architectural type are estimated to have $21-44 \%$ less mass than trees with other growth patterns. Our analysis suggests that accounting for crown allometry would substantially improve the accuracy of tropical estimates of tree biomass and its distribution in primary and degraded forests.
\end{abstract}

Key words: allometric theory; carbon stocks; LiDAR; Madre de Dios; model evaluation; monopodial; Peru; REDD; remote sensing; tree architecture.

\section{INTRODUCTION}

Accurately quantifying the aboveground carbon stocks of tropical forests is essential to understand the role of these ecosystems in the global carbon cycle and to successfully implement payments for ecosystem services, such as those proposed in the United Nations Collaborative Programme on Reducing Emissions from Deforestation or Degradation (REDD/REDD+) (Ebeling and Yasue 2008). Tropical forests store large, but still remarkably uncertain, quantities of carbon (C) in living biomass, with recent estimates ranging from 175 to $340 \mathrm{Pg} \mathrm{C}$ (Houghton et al. 2009, FAO 2010, Pan et al. 2011, Saatchi et al. 2011, Baccini et al. 2012, Feldpausch et al. 2012). Furthermore, uncertainty may increase at smaller scales (Saatchi et al. 2011), which are often the focus of carbon-based projects and where degradation caused by the removal of some of the largest trees is particularly important (Asner et al. 2005). Due to these

Manuscript received 14 January 2013; revised 8 July 2013; accepted 10 September 2013. Corresponding Editor: C. C. Cleveland.

${ }^{1}$ E-mail: rosa.goodman@gmail.com large uncertainties in tree and forest $\mathrm{C}$ estimates, it is unclear exactly how much tropical deforestation, degradation, and sequestration affect global carbon cycling, how forest conservation may slow the rate of climate change, and how much each hectare is valued in the carbon market.

The choice of allometric model used to calculate aboveground biomass (AGB) from forest inventory data is one of the key sources of uncertainty (Chave et al. 2004). Though there are a multitude of published equations, estimates can vary greatly, especially as tree size increases (Baker et al. 2004, Chave et al. 2004). One reason for this is that most models have been developed with very few or even no data from large trees. With few samples in the upper size classes, the relationship between diameter $(D)$ and total AGB can be described by very different mathematical shapes based upon on a single or very few individuals (Houghton et al. 2001, Basuki et al. 2009). These different shapes may be related to variation in height-diameter $(H-D)$ relationships (Aiba and Kohyama 1996, Thomas 1996), the proportion of AGB in the tree crown (Araújo et al. 1999), or structural damage (Chambers et al. 2001), 
which may all vary systematically with tree size, region, or phylogeny, or less predictably among individuals according to local conditions. Overall, these different shapes lead to substantial variation in AGB estimates.

Another key issue causing uncertainty in tropical biomass estimates is the poor sampling across geographic and environmental space in the database used to create both regional and pantropical allometric equations (Houghton et al. 2009). For example, one widely used pantropical database (Chave et al. 2005) comprises many trees from Southeast Asia, Central America, and eastern and central Amazonia, but none from Africa or the southwestern one-third of Amazonia. Together, these lacunae represent nearly half of the tropical forest biome. A new pantropical biomass data set (Feldpausch et al. 2012) has added some data from Africa, southern Brazil, and Indonesia, but still omits much of Africa and South America. This is problematic because a number of important factors, such as species composition and wood density ( $\rho$; Baker et al. 2004), stem turnover (Quesada et al. 2012), forest structure (Banin et al. 2012), maximum height (Banin et al. 2012), $H-D$ relationships (Nogueira et al. 2008b, Feldpausch et al. 2011, Alvarez et al. 2012, Banin et al. 2012), and crown size (Barbier et al. 2010), vary across the tropics, implying that allometric relationships between measurable variables and total AGB of individual trees may also differ by region. For example, trees in Southeast Asia are much taller than trees of the same $D$ in South America, and trees in northeastern Amazonia are taller than those in northwestern and southern Amazon forests (Feldpausch et al. 2011). However, crown size across Amazonia shows a different pattern: Satellite imagery suggests that crown size is larger in southern compared to northern moist Amazonian forests (Barbier et al. 2010). When equations are created using data from a specific geographic region or group of regions, they incorporate a particular relationship between whichever explanatory variables are included in the model and AGB. As a result, applying these equations to predict the biomass of trees in other regions may be inappropriate (Nelson et al. 1999, Clark and Clark 2000, Ketterings et al. 2001, Nogueira et al. 2008a).

Thus, a key requirement for developing more accurate allometric equations is to incorporate all of the appropriate structural variables that affect AGB, including those that vary geographically, such as $\rho, H$, and crown width. Two recent studies have begun to address this by accounting for tree height variation across Amazonia (Nogueira et al. 2008b) and the tropics (Feldpausch et al. 2012). Both studies first created new allometric equations from directly measured biomass data. Then, they developed regional $H-D$ relationships from several areas across Amazonia or the tropics and used these estimated heights, in addition to measured $D$ and $\rho$, to estimate tree biomass at broader scales. The resulting estimates of AGB density were substantially lower in many forest types than had previously been estimated. For example, these studies calculated that using estimated heights resulted in a $6-11 \%$ reduction forest AGB estimates in southwestern Amazonia (Nogueira et al. 2008b), a $16 \%$ reduction in the western Amazon (Feldpausch et al. 2012), and a 14\% reduction across Amazonia (Feldpausch et al. 2012) compared to estimates made without explicitly accounting for $H$. However, the tree-level estimates were not compared to directly measured biomass data in most of the highly affected areas and do not account for variation in crown mass, which may contribute substantially to tree AGB.

The role of tree crowns has also been largely overlooked in theoretical biomass work. Allometric scaling theory was initially based on the relationship between AGB and $D$ alone. For example, in the "WBE" theoretical model (West et al. 1997), tree mass $=a D^{b}$, where $b$ is a universal scaling exponent with a value of $8 /$ 3 based on an idealized vascular architecture (West et al. 1999). Later, $a$ was proposed to be related to $\rho$ (Enquist et al. 1999, Pilli et al. 2006), and the relationship between AGB and $D$ was suggested to be dependent on $H-D$ relationships (Ketterings et al. 2001, Zianis 2008). However, crown characteristics have only recently begun to be incorporated into this framework (Mäkelä and Valentine 2006, Lines et al. 2012), despite early findings that the proportion of crown mass affects AGB worldwide even after considering $D$ and $H$ (Cannell 1984). Variation in crown mass has yet to be tested in empirical tropical studies or applied to practical models to estimate biomass. In a benchmark biomass study (Chave et al. 2005), allometric models including $H$ were based on the theory of tree shape being intermediate between a cylinder and cone, where the mass can be predicted by multiplying tree basal area, $\rho, H$, and a form factor based on stem taper. Again, these models do not account for any variation in the contribution of crown mass, though the size and quantity of branches should influence tree mass beyond that explained by $D$ and $H$. Furthermore, the contribution of crown mass may change as the tree develops and in relation to the surrounding vegetation. For example, when trees emerge from the canopy, vertical height growth slows while horizontal branch growth increases (Sterck and Bongers 2001), but generic allometric models may struggle to capture this behavior because canopy height and light availability varies among different forest types. It follows that we expect that trees growing in lower canopy forests to have proportionally greater crown mass than trees of the same $D$ in taller forests. Accordingly, we might expect that the lack of consideration of crown mass variation and large spatial gaps in directly measured biomass data may together contribute considerable uncertainty to AGB estimates across unsampled areas and forest types.

Incorporating both crown size and tree height, particularly of large trees, may improve estimates from remote-sensing data for both standing carbon stocks and carbon stock changes due to deforestation, selective 


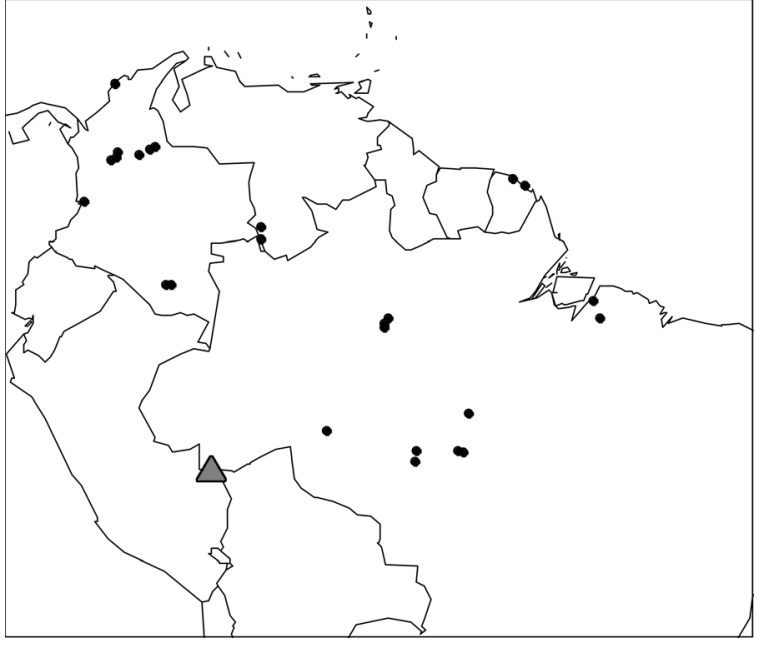

FIG. 1. Location of all biomass data sets collected within tropical South America, including our site (gray triangle). Coordinates from published data (black circles) were obtained directly from tables in Chave et al. (2005) and Alvarez et al. (2012), and ascertained from Nogueira et al. (2008a) and associated publications (Nogueira et al. 2006, 2007).

logging, and other forest degradation. This may be especially applicable to methods based on small footprint light detection and ranging (LiDAR). LiDAR is an emerging technology with potential to achieve relatively low-cost estimates of tropical forest carbon stocks (Lefsky et al. 2002, Asner et al. 2009, 2010), which could be used to support emerging REDD/ REDD+ projects (Asner 2011, Saatchi et al. 2011). Most research has focused on forest canopy height to estimate AGB (Drake et al. 2003, Asner 2009, Asner et al. 2010), but small footprint LiDAR data can also detect both crown area and height of individual trees (Morsdorf et al. 2004, Bortolot and Wynne 2005, Kato et al. 2009, Thomas et al. 2013). Other techniques have also shown promise at detecting individual (IKONOS; Clark et al. 2004) or mean tree crown size (Google Earth; Barbier et al. 2010) over larger areas. Thus, estimating AGB of emergent trees directly from these two parameters, crown area and $H$, may avoid error associated with first estimating $D$ from $H$ or crown diameter (e.g., Zhou et al. 2010).

To test the possible importance of crown size and architecture on AGB estimates, we harvested and weighed trees in a previously unsampled region: southwestern Amazonia, which spans nearly 75 million ha ("Southwest Amazon Moist Forests" terrestrial ecoregion; Olson et al. 2001). Specifically, we worked in Madre de Dios, Peru, which is currently experiencing rapid immigration and development, largely due to the completion of the Interoceanic Highway (Oliveira et al. 2007, Asner et al. 2010), and is the site of many upcoming REDD/REDD+ projects (Rendón Thompson et al. 2013). We hypothesized that, although trees are relatively short in southwestern Amazonia (Nogueira et al. 2008b, Feldpausch et al. 2011), larger crowns (Barbier et al. 2010) will at least partially compensate for their lower stature, and accounting for tree height but ignoring crown dimensions will systematically underestimate AGB. Specifically, we (1) tested the importance and influence of crown dimensions and architecture on AGB; (2) examined the suitability of applying published allometric equations, using different explanatory variables, to estimate AGB of trees in a previously unrepresented region; and (3) created the first allometric equations for this area, with a focus on models that account for crown size and which are of practical application for estimating AGB from both ground and remotely sensed data.

\section{Materials And Methods}

\section{Study site}

This study was carried out in the Maderacre forestry concession near Iñapari, Madre de Dios, Peru, which lies in southwestern Amazonia (Fig. 1). The forest is broadly classified as lowland moist forest (Achard et al. 2002) or terra firme, moist, semi-evergreen rain forest (Whitmore 1998). In our study area, bamboo is sometimes present but does not dominate the understory, and the vertical canopy structure is uneven but closed. The forest within the concession has never been intensively harvested. Mean annual temperature is $24.5^{\circ} \mathrm{C}$, and mean annual precipitation is $1811 \mathrm{~mm}$, distributed seasonally (Hijmans et al. 2005). The dry season usually extends from May to September (3-4 months), and mean precipitation is $113 \mathrm{~mm}$ during the driest quarter and $724 \mathrm{~mm}$ in the wettest quarter (Hijmans et al. 2005). Land type is classified by FAO et al. (1998) as medium gradient hills with an elevation range from approximately 250 to 375 $\mathrm{m}$ above sea level.

\section{Sample selection}

An exploratory survey of the concession was used as a guide to sample both the species and functional composition of the forest with equal numbers of individuals from different diameter classes. In 2005, the company established 66 transects on an unstratified grid $(2 \times 2.5 \mathrm{~km})$ throughout the entire 50000-ha concession: Trees with $D \geq 30 \mathrm{~cm}$ were measured in 500 $\times 10 \mathrm{~m}$ transects, and trees with $D \geq 10 \mathrm{~cm}$ were measured in the central $100 \times 10 \mathrm{~m}$ section of the transect. All individuals fitting the diameter size criteria were included in this survey, regardless of commercial value, trunk or crown form, hollowness, structural damage, or any other irregularities. For the current study, scientific names were matched with the common names reported in the exploratory survey using available resources (Maderacre 2009) and local expertise. Wood density values were then assigned to each species or genus according to the Global Wood Density Database (Chave et al. 2009, Zanne et al. 2009). Next, we used these data to calculate the most common species and 
average $\rho$, excluding palms, in each 20 -cm diameter size class $(10 \leq D<30,30 \leq D<50, \ldots, D \geq 110 \mathrm{~cm})$.

We selected an equal number of trees in each $20-\mathrm{cm} D$ size class for the destructive biomass sampling within the area of annual harvest, but independently of the company surveys and commercial operations. Within each size class, we identified species according to their natural abundance and $\rho$ so that mean $\rho$ of the sample was approximately equal to that of the forest. We avoided bias towards selecting trees with "perfect" form by including the first individual that met our criteria $(D$ and species). In total, 51 trees were harvested and weighed during 2010 and 2011. Of the trees harvested, four had some amount of crown damage and five had rotten or hollow sections in the stem or branches. Timber quality was not specifically assessed, but seven trees had branch scars on the bole, bent stems, very fluted trunks, or substantial portions of rotten wood or hollowness in the bole.

\section{Preharvest measurements}

$D$ was measured at $1.3 \mathrm{~m}$ above the ground or directly above buttresses. Point of measurement (POM) was marked on each tree and recorded. Crown radius was measured as the distance from the midpoint of the trunk to the projected edge of the crown in four cardinal directions (Kitajima et al. 2005, Poorter and Bongers 2006). Canopy quality was recorded as good (symmetrical and vigorous), average (some defects with respect to the symmetry and density of the foliage), or poor (not vigorous, substantial portions of the limbs without foliage or branching, markedly asymmetrical) (JiménezRojas et al. 2002). Crown illumination index was assessed on a scale from 1 to 5 (Dawkins and Field 1978, Keeling and Phillips 2007). Crown architecture (branching patterns) was classified as monopodial (i.e., one main stem), dividing, or changing in orientation, based on Hallé et al. (1978). Prominent branch orientation was recorded as vertical, horizontal, or a combination of these. Notes were taken of any damage (e.g., hollow stem, broken branches) or irregularity (e.g., fluted or swollen stem, buttresses).

\section{Biomass data collection}

Selected trees were felled, remeasured, and weighed in the field. $D$ was measured at the same POM as pre-felling. Total height $(H)$ and height of the first major branch $(>5$ $\mathrm{cm}$ diameter at base or first branch of any size on small trees without branches $>5 \mathrm{~cm}$ diameter; $H_{\mathrm{FMB}}$ ) were measured with metric tape on fallen trees. For all measurements, the base (i.e., $0 \mathrm{~m}$ ) was considered to be mineral soil level on the high side of the trunk. Crown was defined as everything above the first major branch.

Biomass data collection began immediately after trees were cut. The tree was separated into small branches $(<10 \mathrm{~cm}$ diameter) with attached leaves and fruit, large branches ( $\geq 10 \mathrm{~cm}$ diameter), bole, and stump. The stump was cut at ground level. Fresh mass of branches, leaves, noncommercial bole, and the stump were measured in the field with a $250-\mathrm{kg}$ capacity scale with $0.1-\mathrm{kg}$ precision. Fresh mass of commercial boles and some of the very large branches were measured with a $6000-\mathrm{kg}$ capacity scale (5-kg precision) attached to a fork lift. The mass of 10 stems was estimated from volume measurements based on length and diameter measurements every $1 \mathrm{~m}$ on each $\log$ section. Buttresses and any irregular parts were cut and weighed directly so that volume was estimated from only cylindrical sections.

To estimate moisture content and $\rho$, wood samples of each tree part (top and bottom of commercial bole, large branches, and small branches) were taken from freshly cut wood. When the stem was cut into more than two sections, a sample was collected from the bottom or top of every section (with the top of one section corresponding to the bottom of the next). Wood samples were cut as disks of constant thickness in small branches and as wedges of constant thickness, extending from the centre to the bark, in large branches and stems (minimum $100 \mathrm{~g}$ ). Fresh mass was measured immediately with a hanging scale with 1 -g precision.

All individuals were identified to species with botanical vouchers collected from each tree, except when no leaves were present at the time of felling. Botanical samples were dried, stored, and identified at the Universidad Nacional de San Antonio Abad del Cusco (CUZ; Cusco, Peru) in 2010 and Universidad Nacional Amazónica de Madre de Dios (GHMDD; Puerto Maldonado, Peru) in 2011.

\section{Laboratory work and data preparation}

Wood samples were transported to the laboratory for further analysis. Wood density was only assessed for stem wood, and green volume was measured by water displacement on a digital scale with 5-g precision. For moisture content and $\rho$, all wood samples were dried at $101^{\circ} \mathrm{C}$ (Williamson and Wiemann 2010), and dry mass was recorded after three consecutive days of constant mass with a digital scale with 1-mg precision. Wood density was calculated as the ratio of dry mass to fresh volume (dry mass/fresh volume). Moisture content was calculated as the difference between fresh and dry mass per unit fresh mass ([fresh mass - dry mass]/fresh mass). Dry mass for each tree part was calculated as fresh mass times the proportion of wood dry mass (fresh mass $\times[1$ - moisture content]) or as volume multiplied by $\rho$. Dry mass of the each stem section was calculated as the mean of the two applicable moisture content or $\rho$ values (e.g., top and bottom of the section).

Crown depth was calculated as the distance from the first major branch to the top of the canopy $(\mathrm{CDepth}=H$ $\left.-H_{\mathrm{FMB}}\right)$. Average crown radius (CR) was the mean of the four crown radius measurements. Crown ellipse area (CEA) was calculated as $\pi \times\left(\mathrm{CR}_{\mathrm{NS}}\right) \times\left(\mathrm{CR}_{\mathrm{EW}}\right)$, where $\mathrm{CR}_{\mathrm{NS}}$ and $\mathrm{CR}_{\mathrm{EW}}$ are the average crown radii for the $\mathrm{N}-$ $\mathrm{S}$ and $\mathrm{E}-\mathrm{W}$ directions, respectively. "Crown mass" was 
the sum of large branches, small branches, and attached leaves and fruit.

\section{Evaluating existing models}

We estimated AGB of our trees using 38 published equations. Models were obtained from four pantropical studies (Brown et al. 1989, Chave et al. 2005, Djomo et al. 2010, Feldpausch et al. 2012), four original Amazonian studies (central Amazonia [Higuchi et al. 1998, Chambers et al. 2001], southern Brazil [Nogueira et al. 2008a], and Colombia [Alvarez et al. 2012]), two adjusted Amazonian equations (Baker et al. 2004, Nogueira et al. 2008b), a global model (Zianis 2008), and a theoretical model (West et al. 1997). When applicable, we examined the equations for both "moist" and "all" forest types. Two models are reported by Chambers et al. (2001): one in which all trees with $D \geq 5$ $\mathrm{cm}(\mathrm{Cham} \geq 5)$ were included and another restricted to trees $D>10 \mathrm{~cm}($ Cham $>10)$.

For the Higuchi estimates, dry mass was calculated by multiplying fresh mass estimates (as given by the published model) by 0.6028 ( 1 - mean moisture content). AGB corrections for $H$ (Nogueira et al. $2008 \mathrm{~b}$ ) were made by multiplying the Higuchi estimates by $\left[0.66\left(H_{\mathrm{SW}} / H_{\mathrm{C}}\right)+0.34\right]$, where $H_{\mathrm{SW}}$ and $H_{\mathrm{C}}$ were estimated heights for trees in the southwestern dense forests and central Amazonian forests, respectively, using the ln-transformed $H-D$ equations. A correction factor $\left(\mathrm{CF}=\exp \left[\mathrm{RSE}^{2} / 2\right]\right)$ was applied to backtransformed predicted values to remove the bias from predictions made on log-transformed data (Baskerville 1972, Chave et al. 2005), except for the Higuchi model because there was no mention of whether a correction factor was included in the methods used to develop the modified models described by Nogueira et al. (2008b).

We compared values predicted (pred) by each model to observed (obs) values measured in this study. Errors (Mg) were calculated on the original scale as $\mathrm{AGB}_{\text {pred - }}$ $\mathrm{AGB}_{\text {obs }}$, and relative error (\%) was calculated as $\left(A G B_{\text {pred }}-\mathrm{AGB}_{\mathrm{obs}}\right) / \mathrm{AGB}_{\mathrm{obs}} \times 100 \%$, so that negative values indicate underestimates and positive values indicate overestimates. Overall predictability was assessed by standard deviation of the relative errors $\left(\mathrm{SD}_{\mathrm{RE}}\right.$; Chave et al. 2005). We also compared the equations based on true error criteria: mean error $\left(\right.$ mean $\left._{\mathrm{E}}\right)$, standard deviation of the errors $\left(\mathrm{SD}_{\mathrm{E}}\right)$, sum of errors, and $R^{2}(1-\mathrm{SSE} / \mathrm{SST})$. Results are also discussed as mean percent error (mean $\% \mathrm{E}$ $=$ mean $_{\mathrm{E}} /$ mean $\mathrm{AGB} \times 100 \%$ ).

\section{Testing the importance of crown dimensions and architecture in new allometric models}

Linear models were used to test the importance of different structural variables $\left(D, \mathrm{POM}, H, H_{\mathrm{FMB}}, \rho\right.$, CDepth, and CR) for predicting total tree AGB. For all variables except $\mathrm{CR}$ and $\mathrm{CEA}$, postharvest measurements were used for the data analysis. CR and CEA were too highly correlated with one another $(r>0.95)$ to include in the same model, but no other explanatory variables presented problems with multicollinearity. Therefore, we used the crown variable that would be directly assessed: CEA for remote-sensing models and CR for all others.

To determine the most robust models using different explanatory variables and to test the significance of crown dimensions and other structural parameters, we built new models via three different methods: (1) based on the six model forms developed by Chave et al. (2005) using $D, \rho$, and $H$; (2) adding continuous and categorical variables to these six base models to account for crown dimensions, architecture, quality, and illumination index; structural damage; and stem irregularities; and (3) starting with all seven continuous variables (previous paragraph) and using backwards elimination until a minimum adequate model was reached. We also constructed models to estimate biomass directly from $H$ and crown area, which can be obtained from remotesensing data, and from $D$ and $H$ to estimate mass from simple forest inventories. For backward elimination, we used the "dropterm" function and $F$ test in the MASS package in $\mathrm{R}$ ( R Core Development Team 2013) until all variables were significant $(P<0.05)$.

All data were transformed to the natural logarithm for analysis to follow allometric theory, based on powerlaw relationships, and the error structure of the data. As per the nature of most biomass data, variation increases with increasing $D$. Thus, the error term should be multiplicative, as modeled by log-transformed linear regression, rather than additive, as assumed in most nonlinear models (Mascaro et al. 2011, Xiao et al. 2011). Homogeneous variance and linearity were evaluated by plotting residuals against fitted values. Normality of the residuals was tested using normal Q-Q plots (standardized residuals vs. theoretical quantiles) and the Anderson-Darling test of normality. In the case of non-normal distribution, we performed the Box-Cox procedure to determine an appropriate transformation. If the $95 \%$ confidence interval for $\lambda$ included 1 , indicating that no transformation was necessary, we considered that the log-linear models were adequate.

Models were compared using $R^{2}$, Akaike's information criterion (AIC), and the residual standard error (RSE). We also manually calculated errors on the original, rather than logarithmic, scale and compared predictions by the same methods used to compare published models. The proportion of variation marginally explained by each variable was assessed by dividing Type III sum of squares for each variable by the total sum of squares. Type III sum of squares was calculated using the "Anova" function in the "car" package; all statistical analysis was performed using the $\mathrm{R}$ statistical package, version 2.15.2 (R Core Development Team 2013).

\section{Results}

\section{Biomass and allometric relationships}

Fifty-one trees were weighed, representing 41 species, 38 genera, and 17 families. Diameters ranged from $10.6 \mathrm{~cm}$ to 


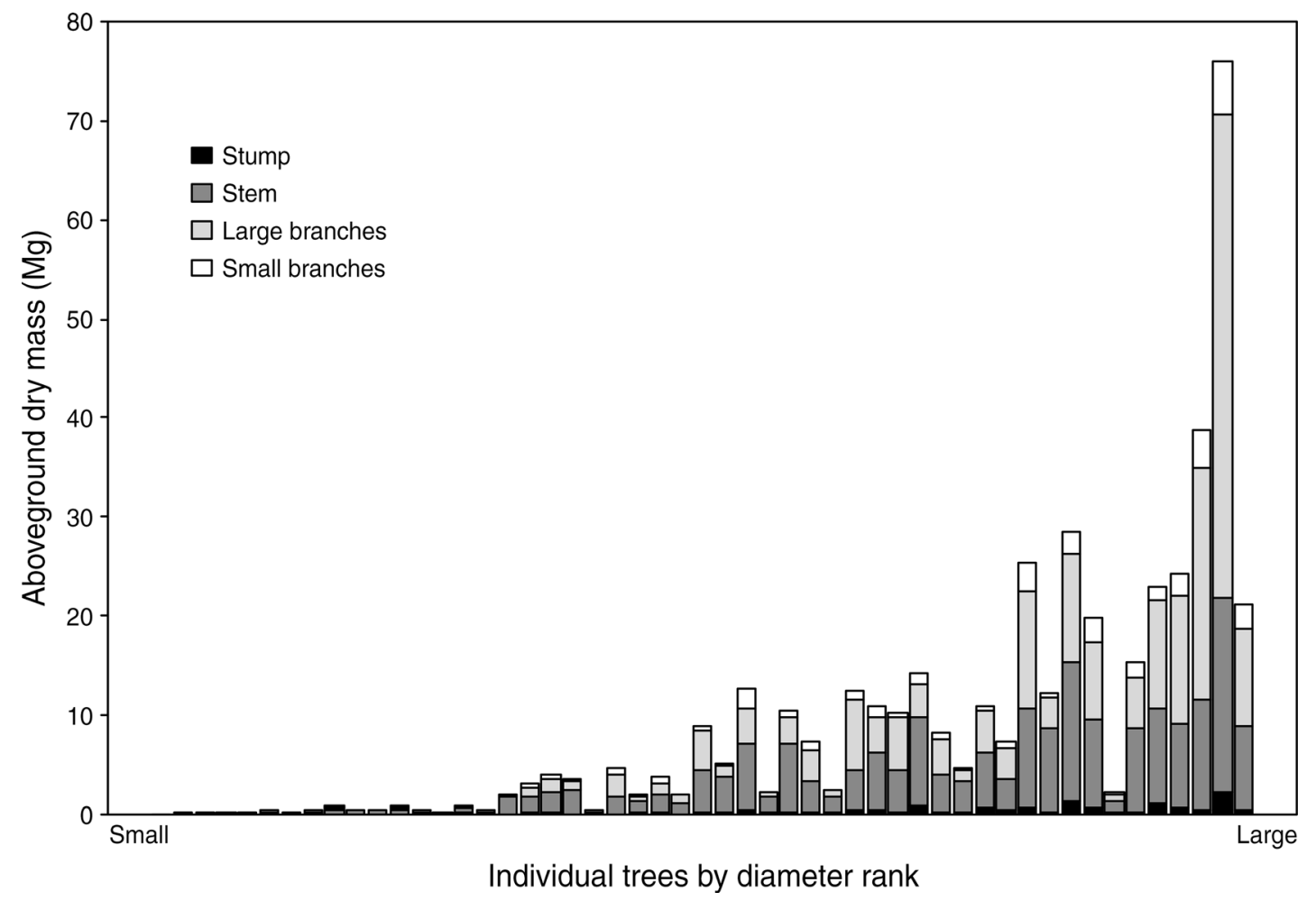

FIG. 2. Aboveground dry mass in each part (small branches and leaves, large branches, stem, and stump) of the 51 trees harvested and weighed in this study. These data are available in the Dryad data repository (available online, see footnote 2).

$169.0 \mathrm{~cm}$, including 12 trees with $D>100 \mathrm{~cm}$. Single-tree AGB varied between $0.042 \mathrm{Mg}$ to the most massive tropical tree ever weighed, $76 \mathrm{Mg}$ (Fig. 2; Goodman et al. 2012). The fraction of total AGB in the crown ranged from $14 \%$ to $71 \%$ with a mean $( \pm$ SE) of $44 \% \pm 2 \%$. Wood density and moisture content of samples varied greatly both between and within individuals (Appendix A). Overall, $\rho$ in the destructively sampled trees was close to that of the whole stand, and especially so for the largest size class (Table 1). This data set is available from the Dryad data repository (available online). ${ }^{2}$

$H-D$ relationships were explored to identify the relationship between these two variables and to test model predictions from estimated, rather than directly measured, heights. The following power-law relationship best fit our data:

$$
H=4.871 \times D^{0.4407}
$$

where $H$ is total height $(\mathrm{m}), D$ is diameter at $1.3 \mathrm{~m}$ or above buttresses $(\mathrm{cm})$, and the correction factor for back-transforming estimates has been incorporated $\left(R^{2}\right.$ $=0.737$ in log-transformed models; $P<0.001$ ).

\section{Evaluating existing models}

Most equations were poor predictors of AGB for our southwestern Amazonian trees, primarily due to poor

\footnotetext{
${ }^{2}$ http://datadryad.org/resource/doi:10.5061/dryad.p281g/1
}

estimates of the largest trees. On the original scale $(\mathrm{Mg})$, $R^{2}$ ranged from 0.019 to 0.884 (Table 2). Choice of the "best" equation depends on the evaluation criteria used: $R^{2}$, mean and $\mathrm{SD}$ of true errors $\left(\operatorname{mean}_{\mathrm{E}}\right.$ and $\left.\mathrm{SD}_{\mathrm{E}}\right)$, and mean and $\mathrm{SD}$ of relative errors $\left(\operatorname{mean}_{\mathrm{RE}}\right.$ and $\left.\mathrm{SD}_{\mathrm{RE}}\right)$. Often, conflicting conclusions could be drawn from true and relative errors because of differences among diameter size classes, with the largest trees having a dominant influence on true errors. Furthermore, many models created from the same data sets, but using different model forms and explanatory variables, showed very different results (e.g., Alv, Ch, and Feld; see Table 2 for study abbreviations).

All models with $D$ as the only explanatory variable performed poorly across all size classes. Models with the polynomial $D$ form (e.g., Cham) severely underestimated AGB of the largest trees, leading to large overall underestimates for our 51 trees. Including $\rho$ greatly improved both precision and accuracy of estimates. In fact, the Ch II.6 equation appeared to best predict AGB among all the equations evaluated. Again, all models with a polynomial $D$ form underestimated AGB of the largest size class, with the exception of Feld 1; and, on average, the models without polynomial terms for $D$ performed better (Table 2).

Models including $H$ did not consistently improve estimates. Published models with $H$ regularly underestimated AGB and had lower overall predictability (i.e., greater $\mathrm{SD}_{\mathrm{RE}}$ ) compared to models which only used $D$ 
TABLE 1. Wood density statistics (mean, lower [LCL], and upper [UCL] 95\% confidence limits) and sample size (n) in each diameter $(D)$ size class for trees southwestern Amazonia.

\begin{tabular}{|c|c|c|c|c|c|c|c|c|}
\hline \multirow[b]{2}{*}{ Diameter class $(\mathrm{cm})$} & \multicolumn{4}{|c|}{ Forest inventory } & \multicolumn{4}{|c|}{ Biomass samples } \\
\hline & $n$ & Mean & LCL & UCL & $n$ & Mean & LCL & UCL \\
\hline $10 \leq D<30$ & 1117 & 0.561 & 0.552 & 0.569 & 8 & 0.598 & 0.517 & 0.679 \\
\hline $30 \leq D<50$ & 949 & 0.545 & 0.534 & 0.556 & 10 & 0.473 & 0.348 & 0.598 \\
\hline $50 \leq D<70$ & 373 & 0.562 & 0.543 & 0.581 & 7 & 0.586 & 0.44 & 0.733 \\
\hline $70 \leq D<90$ & 115 & 0.548 & 0.517 & 0.578 & 8 & 0.619 & 0.508 & 0.731 \\
\hline $90 \leq D<110$ & 50 & 0.63 & 0.572 & 0.688 & 10 & 0.657 & 0.535 & 0.78 \\
\hline$D \geq 110$ & 41 & 0.551 & 0.474 & 0.627 & 8 & 0.55 & 0.411 & 0.69 \\
\hline
\end{tabular}

Notes: Wood density values $\left(\mathrm{g} / \mathrm{cm}^{3}\right)$ for trees in the forest inventory were deduced from matching scientific names to common names and applying values from a Global Wood Density Database (Chave et al. 2009, Zanne et al. 2009); wood density of destructive biomass samples was obtained from tree stems measured in this study.

TABLE 2. Summary of errors (sum, mean, standard deviation [SD], and coefficient of correlation $\left[R^{2}\right]$ ) and relative error (Rel. Err.; mean and SD) for each published equation examined in this study.

\begin{tabular}{|c|c|c|c|c|c|c|c|c|c|c|}
\hline \multirow[b]{2}{*}{ Model } & \multirow{2}{*}{$\begin{array}{c}\text { Forest } \\
\text { type }\end{array}$} & \multirow[b]{2}{*}{ Location } & \multirow[b]{2}{*}{$n$} & \multirow[b]{2}{*}{ Form } & \multicolumn{4}{|c|}{ Error $(\mathrm{Mg})$} & \multicolumn{2}{|c|}{ Rel. Err. (\%) } \\
\hline & & & & & Sum & Mean & SD & $R^{2}$ & Mean & SD \\
\hline Nog & open & S Amazon & 262 & $D$ & -29 & -0.57 & 7.9 & 0.64 & 70 & 179 \\
\hline Higuchi & moist & C. Amazon & 315 & $D$ & -58 & -1.14 & 8.2 & 0.60 & 81 & 194 \\
\hline Djo P2 & moist & tropical & 443 & $D$ & 136 & 2.67 & 8.3 & 0.56 & 117 & 291 \\
\hline Cham $>10$ & moist & C. Amazon & 161 & $D+D^{2}+D^{3}$ & -54 & -1.07 & 8.9 & 0.53 & 111 & 243 \\
\hline Zianis & all & global & 1211 & $D$ & -179 & -3.50 & 9.1 & 0.44 & 12 & 118 \\
\hline Cham $\geq 5$ & moist & C. Amazon & 315 & $D+D^{2}+D^{3}$ & -168 & -3.29 & 10.6 & 0.28 & 74 & 210 \\
\hline Mean for all models with only $D$ & & & & & -3 & -0.06 & 9.2 & 0.44 & 91 & 209 \\
\hline Ch II.6 & all & tropical & 2410 & $D+1 \rho$ & 2 & 0.03 & 5.1 & 0.85 & 24 & 65 \\
\hline Ch II.1 & moist & tropical & 1504 & $D+D^{2}+D^{3}+\rho$ & 23 & 0.45 & 5.1 & 0.85 & 38 & 74 \\
\hline Ch II.3 & moist & tropical & 1504 & $D+D^{2}+D^{3}+1 \rho$ & 18 & 0.36 & 5.2 & 0.84 & 38 & 76 \\
\hline Feld 1 & all & tropical & 1816 & $D+D^{2}+D^{3}+\rho$ & 25 & 0.50 & 5.2 & 0.84 & 41 & 79 \\
\hline Alv II.6 & all & Colombia & 631 & $D+\rho$ & -16 & -0.31 & 5.3 & 0.84 & 27 & 67 \\
\hline Alv II.5 & moist & Colombia & 631 & $D+\rho$ & -29 & -0.57 & 5.4 & 0.82 & 27 & 67 \\
\hline Ch II.4 & all & tropical & 2410 & $D+D^{2}+D^{3}+1 \rho$ & -75 & -1.48 & 6.2 & 0.76 & 15 & 63 \\
\hline Ch II.2 & all & tropical & 2410 & $D+D^{2}+D^{3}+\rho$ & -56 & -1.09 & 6.3 & 0.76 & 28 & 80 \\
\hline Ch II.5 & moist & tropical & 1504 & $D+1 \rho$ & 132 & 2.60 & 5.9 & 0.76 & 52 & 81 \\
\hline Alv II.2 & all & Colombia & 631 & $D+D^{2}+D^{3}+\rho$ & -75 & -1.48 & 7.1 & 0.69 & 30 & 84 \\
\hline Alv II.4 & all & Colombia & 631 & $D+D^{2}+D^{3}+1 \rho$ & -91 & -1.79 & 7.1 & 0.69 & 20 & 69 \\
\hline Alv II.3 & moist & Colombia & 370 & $D+D^{2}+D^{3}+1 \rho$ & -133 & -2.60 & 8.0 & 0.59 & 16 & 69 \\
\hline Alv II.1 & moist & Colombia & 370 & $D+D^{2}+D^{3}+\rho$ & -141 & -2.77 & 8.9 & 0.49 & 34 & 115 \\
\hline Baker & moist & Amazon & 315 & $D+D^{2}+D^{3}+\rho$ & -213 & -4.19 & 10.1 & 0.30 & 5 & 73 \\
\hline Mean for all models with $D$ and $\rho$ & & & & & -45 & -0.88 & 6.5 & 0.72 & 28 & 76 \\
\hline (not including those with $D^{2}$ and $D$ & & & & & 22 & 0.44 & 5.4 & 0.82 & 33 & 70 \\
\hline Alv I.6 & all & Colombia & 631 & $1 \rho D^{2} H$ & 51 & 1.01 & 4.3 & 0.88 & 38 & 66 \\
\hline Ch I.3 & moist & tropical & 1348 & $\rho D^{2} H$ & -37 & -0.73 & 4.9 & 0.86 & 12 & 53 \\
\hline Ch I.6 & all & tropical & 2410 & $1 \rho D^{2} H$ & -36 & -0.72 & 4.9 & 0.85 & 14 & 54 \\
\hline Ch I.1 & moist & tropical & 1348 & $D+\rho+H$ & -8 & -0.15 & 5.0 & 0.85 & 25 & 69 \\
\hline Ch I.5 & moist & tropical & 1348 & $1 \rho D^{2} H$ & -51 & -1.00 & 5.1 & 0.84 & 10 & 52 \\
\hline Ch I.2 & all & tropical & 2410 & $D+\rho+H$ & -32 & -0.63 & 5.3 & 0.83 & 21 & 67 \\
\hline Alv I.5 & moist & Colombia & 370 & $1 \rho D^{2} H$ & 133 & 2.61 & 4.6 & 0.83 & 61 & 77 \\
\hline Ch I.4 & all & tropical & 2410 & $\rho D^{2} H$ & -58 & -1.14 & 5.3 & 0.83 & 10 & 53 \\
\hline Feld 2 & all & tropical & 1816 & $D^{2} H \rho$ & -60 & -1.19 & 5.3 & 0.83 & 9 & 53 \\
\hline Alv I.3 & moist & Colombia & 370 & $\rho D^{2} \dot{H}$ & -55 & -1.09 & 5.6 & 0.81 & 21 & 62 \\
\hline Brown & moist & tropical & 94 & $\rho D^{2} H$ & -63 & -1.24 & 5.6 & 0.81 & 16 & 58 \\
\hline Alv I.4 & all & Colombia & 631 & $\rho D^{2} H$ & -62 & -1.22 & 5.7 & 0.80 & 20 & 62 \\
\hline Alv I.1 & moist & Colombia & 631 & $\boldsymbol{D}+\boldsymbol{\rho}+\boldsymbol{H}$ & 4 & 0.08 & 6.0 & 0.79 & 50 & 113 \\
\hline Alv I.2 & all & Colombia & 631 & $D+\rho+H$ & -78 & -1.53 & 6.2 & 0.76 & 19 & 72 \\
\hline Djo P5 & moist & tropical & 274 & $D^{2}+D^{3}+D^{2} H+\rho$ & -17 & -0.33 & 6.9 & 0.72 & 66 & 143 \\
\hline Nog H & moist & SW Amazon & $\mathrm{n} / \mathrm{a}$ & $D \times H_{\text {corr }}$ & -80 & -1.56 & 8.4 & 0.57 & 69 & 182 \\
\hline Nog $\mathrm{H}-\rho$ & moist & SW Amazon & $\mathrm{n} / \mathrm{a}$ & $D \times H_{\text {corr }} \times \rho_{\text {corr }}$ & -137 & -2.69 & 8.9 & 0.50 & 43 & 154 \\
\hline Alv I.6 & all & Colombia & 631 & $1 \rho D^{2} H$ & 51 & 1.01 & 4.3 & 0.88 & 38 & 66 \\
\hline Mean for all models with $D, \rho$, and $H$ & & & & & -35 & -0.68 & 5.8 & 0.79 & 30 & 82 \\
\hline
\end{tabular}

Notes: For models, numbers, Roman numerals, and letters following first author names refer to specific models within each study. In the Location column, C. refers to Central; in the Forms column, "1" indicates the parameter coefficient being constrained to 1 ; and $n$ is the sample size used to create each model. Abbreviations are: diameter, $D(\mathrm{~cm}) ;$ wood density, $\rho\left(\mathrm{g} / \mathrm{cm}^{3}\right)$; and total height, $H(\mathrm{~m})$. Models are arranged from highest to lowest $R^{2}$ among all equations with the same explanatory variables. Numbers in boldface type indicate the "best" (highest $R^{2}$ or lowest absolute value of all other criteria) within each group of equations, and the corresponding model information is also in boldface. Model reference abbreviations are: Alv, Alvarez et al. 2012; Baker, Baker et al. 2004; Brown, Brown et al. 1989; Ch, Chave et al. 2005; Cham, Chambers et al. 2001; Djo, Djomo et al. 2010; Feld, Feldpausch et al. 2012; Nog, Nogueira et al. 2008a; Nog H and H- $\rho$, Nogueira et al. 2008b; WBE, West et al. 1997; and Zianis, Zianis 2008. 

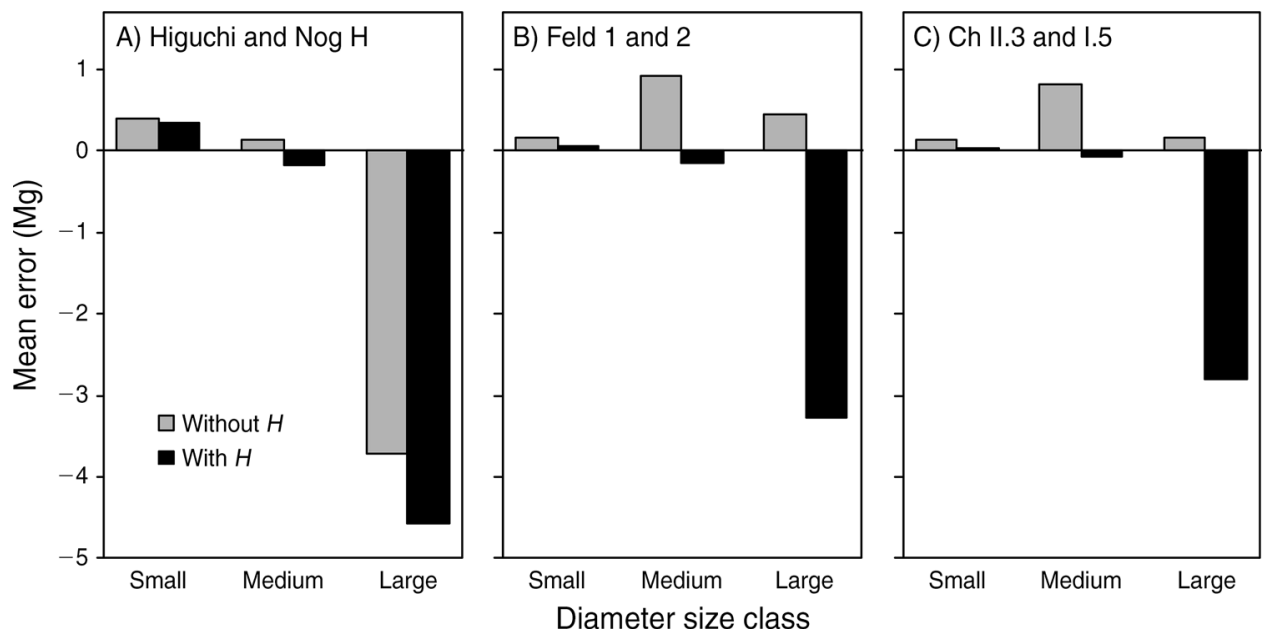

FIG. 3. Mean error in estimates (predicted aboveground biomass minus observed aboveground biomass $\left[\mathrm{AGB}_{\mathrm{pred}}-\mathrm{AGB}_{\mathrm{obs}}\right]$ )

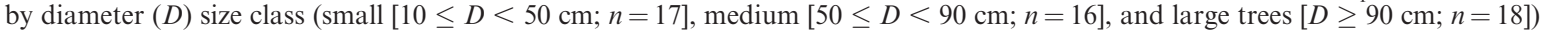
for three key model pairs. Models are (A) Higuchi et al. (1998) and Nogueira et al. (2008b) with height correction, (B) Feldpausch et al. (2012) 1 and 2, and (C) Chave et al. (2005) II.3 and I.5 for moist forests, listed without and with height $(H)$, respectively. See Table 2 for clarification of the study abbreviations.

and $\rho$ (Table 2). The effect of $H$ on AGB estimates can be more clearly identified by comparing specific pairs of models from the same study that include and exclude $H$. Models without $H$ often overestimated AGB, but models with $H$ always resulted in large underestimates, primarily due to severe underestimates of the largest trees (Fig. 3). In the two studies that downgraded AGB of the southwestern Amazon based on tree height (Nogueira et al. 2008b, Feldpausch et al. 2012), we found that including $H$ improved estimates by some measures (lowered mean ${ }_{\mathrm{RE}}$ and $\mathrm{SD}_{\mathrm{RE}}$ ), but decreased the accuracy by other measures (increased $\left|\operatorname{mean}_{\mathrm{E}}\right|$ and $\mathrm{SD}_{\mathrm{E}}$ and lowered $R^{2}$ ). The Higuchi model from central Amazonia underestimated AGB of our trees (Higuchi in Table 2), so applying the subsequent $H$ and $\rho$ "corrections" introduced by Nogueira et al. (2008b) only exacerbated these underestimates ( Nog $\mathrm{H}$ and Nog H- $\rho$ in Table 2; Fig. 3). Among the Feld models, AGB was overestimated without $H\left(\right.$ mean $_{\mathrm{E}}=+0.50 \mathrm{Mg} /$ tree in Feld 1), but it was underestimated by over twice this amount when $H$ was included $\left(\operatorname{mean}_{\mathrm{E}}=-1.19 \mathrm{Mg} /\right.$ tree in Feld 2). The same pattern was also observed in the two models recommended by Chave et al. (2005) for moist forests: On average, Ch II.3 (without $H$ ) overestimated AGB by $+0.36 \mathrm{Mg}$ /tree, but Ch I.5 (with $H$ ) underestimated AGB by nearly three times this amount $(-1.00 \mathrm{Mg} /$ tree $)$. Mean estimates by size class show that all three models without $H$ overestimated AGB of small and medium-sized trees $(D<90 \mathrm{~cm})$, but the models that included $H$ underestimated AGB of medium and large trees $(D \geq$ $50 \mathrm{~cm}$ ), with severe underestimates of the largest size class ( $D \geq 90 \mathrm{~cm}$; Fig. 3 ).

\section{New models using diameter, wood density, and height}

Before we could test the importance of crown dimensions for AGB estimates, we first created new models using the three standard variables, $D, \rho$, and $H$. Within our data set, all models with $H$ performed better than all those without $H$, and models with unconstrained variable coefficients performed better than those with constrained coefficients. By all criteria, model I.1 (with $D, \rho$, and $H$ ) performed best (Table 3 ). Of the models without $H$, model II.1 was best, and $R^{2}$ values for models without $H$ rivalled that of models I.1-I.5 (with $H$ ). Unlike models in many other studies, not all terms for $D$ were significant in the polynomial models.

TABLE 3. All models including diameter $(D ; \mathrm{cm})$, wood density $\left(\rho ; \mathrm{g} / \mathrm{cm}^{3}\right)$, and total height $(H ; \mathrm{m})$ to estimate aboveground biomass (AGB; kg dry mass) created from 51 trees with the diameter range $11-169 \mathrm{~cm}$.

\begin{tabular}{|c|c|c|c|c|c|c|c|c|c|c|c|}
\hline Code & Form & $a$ & $b$ & $c$ & $d$ & $R^{2}$ & RSE & AIC & $F$ & df & $P$ \\
\hline I.1 & $\ln (\mathrm{AGB})=a+b \ln (D)+c \ln (H)+d \ln (\rho)$ & -2.6512 & 2.0212 & 0.9302 & 1.3257 & 0.971 & 0.317 & 33.4 & 531 & 3,47 & $<0.001$ \\
\hline I. 3 & $\ln (\mathrm{AGB})=a+b \ln \left(D^{2} H \rho\right)$ & -3.2458 & 1.0221 & $\ldots$ & & 0.967 & 0.332 & 36.1 & 1450 & 1,49 & $<0.001$ \\
\hline I. 5 & $\ln (\mathrm{AGB})=a+\ln \left(D^{2} H \rho\right)$ & -3.0046 & $\ldots$ & $\ldots$ & $\ldots$ & ... & 0.331 & 34.8 & na & na, 50 & $<0.001$ \\
\hline II.1 & $\ln (\mathrm{AGB})=a+b \ln (D)+d \ln (\rho)$ & -1.0165 & 2.4186 & $\ldots$ & 1.5241 & 0.965 & 0.347 & 41.6 & 661 & 2,48 & $<0.001$ \\
\hline II. 3 & $\ln (\mathrm{AGB})=a+b(\ln (D))^{2}+\ln (\rho)$ & 3.1128 & 0.3165 & $\ldots$ & $\ldots$ & 0.951 & 0.399 & 54.9 & 943 & 1,49 & $<0.001$ \\
\hline II.5 & $\ln (\mathrm{AGB})=a+b \ln (D)+\ln (\rho)$ & -1.4823 & 2.4519 & $\ldots$ & $\ldots$ & 0.950 & 0.400 & 55.2 & 933 & 1,49 & $<0.001$ \\
\hline
\end{tabular}

Notes: RSE is residual standard error; df are degrees of freedom (model, error), and na is not applicable. Ellipses indicate that no corresponding parameter is included in the model. 
TABLE 4. All models that include crown dimensions (average crown radius [CR; $\mathrm{m}])$, tree architecture $(M=1$ if monopodial, $M=0$ if not), diameter $(D ; \mathrm{cm})$, wood density $\left(\rho ; \mathrm{g} / \mathrm{cm}^{3}\right)$, and total height $(H ; \mathrm{m})$ to estimate aboveground biomass (AGB; $\mathrm{kg}$ dry mass) created from 51 trees with the diameter range $11-169 \mathrm{~cm}$.

\begin{tabular}{|c|c|c|c|c|c|c|}
\hline Code & Form & $a$ & $b$ & $c$ & $d$ & $f$ \\
\hline I. $1 \mathrm{CR}$ & $\ln (\mathrm{AGB})=a+b \ln (D)+c \ln (H)+d \ln (\rho)+f \ln (\mathrm{CR})$ & -1.8733 & 1.4378 & 0.9379 & 1.0678 & 0.7624 \\
\hline I.3 CR & $\ln (\mathrm{AGB})=a+b \ln \left(D^{2} H \rho\right)+f \ln (\mathrm{CR})$ & -2.1788 & 0.8025 & $\ldots$ & $\ldots$ & 0.7147 \\
\hline I. $5 \mathrm{CR}$ & $\ln (\mathrm{AGB})=a+\ln \left(D^{2} H \rho\right)+f \ln (\mathrm{CR})$ & -3.3639 & & $\ldots$ & & 0.1926 \\
\hline II.1 CR & $\ln (\mathrm{AGB})=b \ln (D)+d \ln (\rho)+f \ln (\mathrm{CR})$ & $\ldots$ & 1.7586 & ... & 1.2708 & 0.8202 \\
\hline II.3/5 CR & $\ln (\mathrm{AGB})=b \ln (D)+\ln (\rho)+f \ln (\mathrm{CR})$ & $\ldots$ & 1.6382 & $\ldots$ & & 0.9931 \\
\hline I. $1 \mathrm{M}$ & $\ln (\mathrm{AGB})=b \ln (D)+c \ln (H)+d \ln (\rho)+f M$ & -2.4821 & 1.9611 & 0.9513 & 1.2297 & -0.2520 \\
\hline I. $3 \mathrm{M}$ & $\ln (\mathrm{AGB})=a+b \ln \left(D^{2} H \rho\right)+f M$ & -2.8205 & 0.9894 & $\ldots$ & $\ldots$ & -0.3145 \\
\hline I. $5 \mathrm{M}$ & $\ln (\mathrm{AGB})=a+\ln \left(D^{2} H \rho\right)+f M$ & -2.9410 & & $\ldots$ & ... & -0.2949 \\
\hline II. $3 \mathrm{M}$ & $\ln (\mathrm{AGB})=a+b\left(\ln (D)^{2}+\ln (\rho)+f M\right.$ & 3.4227 & 0.3040 & .. & .. & -0.4411 \\
\hline II. $5 \mathrm{M}$ & $\ln (\mathrm{AGB})=a+b \ln (D)+\ln (\rho)+f M$ & -1.0299 & 2.3622 & $\ldots$ & $\ldots$ & -0.3966 \\
\hline I.3 CR.M & $\ln (\mathrm{AGB})=a+b \ln \left(D^{2} H \rho\right)+d \ln (\mathrm{CR})+f M$ & -1.9421 & 0.7954 & $\ldots$ & 0.6571 & -0.2387 \\
\hline II. 3 CR.M & $\ln (\mathrm{AGB})=a+b \ln (D)+\ln (\rho)+d \ln (\mathrm{CR})+f M$ & 3.2284 & 0.2350 & $\ldots$ & 0.7207 & -0.2708 \\
\hline
\end{tabular}

Notes: RSE is residual standard error; df are degrees of freedom (model, error); and $\sim \mathrm{N}$ indicates whether residuals were distributed normally using the Anderson-Darling normality test $(P \geq 0.05)$. Ellipses indicate that no corresponding parameter is included in the model.

$\dagger$ From ANOVA comparing this model and an equivalent model with and without the last variable listed (CR or $M)$.

For all models created using $D, \rho$, and $H$, we found that the residuals were not distributed normally, due to a slight negative skew, but the $95 \%$ confidence interval for $\lambda$ always included 1 . In this case, we consider these equations to be reasonably reliable, but they are further evaluated in section Results: Evaluation of all new models.

\section{New models accounting for crown dimensions and architecture}

Beginning with the six base models (Table 3), we then added terms to account for crown size and architecture (Table 4). The effect of the variable for crown size (crown radius; CR) was highly significant $(P<0.001)$ in every model tested. Adding CR greatly improved estimates, increasing $R^{2}$ and reducing RSE and AIC, and models were significantly better than the equivalent equation without CR (Table 4). Furthermore, including CR normalized residuals in most models. Model I.1 CR, with all four variables, was best in terms of having the lowest RSE and AIC and was the minimum adequate model determined by backwards elimination of all seven continuous variables, but model II.1 CR (with $\rho, D, C R$ ) had the greatest coefficient of correlation $\left(R^{2}=0.999\right)$. Including $\mathrm{CR}$ in models was always better than crown ellipse area (CEA), so equations with CEA are not reported.

Several analyses showed that $\mathrm{CR}$ is even more effective than $H$ at explaining variation in AGB. First, the model with $D, \rho, \mathrm{CR}$ (II.1 CR) performed better than the equivalent model with $H$ instead of CR (I.1). Second, when we calculated the proportion of variation in AGB explained marginally by each variable (Type III $\mathrm{SS}$ ) in the model with all four variables (I.1 CR), CR $(10.5 \%)$ was more informative than $H(6.0 \%$; Fig. $4 \mathrm{~A})$. Furthermore, in single-variable models, CR explained the most variation in AGB $(86.6 \%)$, more than $D$ $(85.9 \%)$ or $H(82.8 \%$; Fig. $4 \mathrm{~B})$.
Monopodial $(M)$ was the only significant architectural variable in the models tested (Table 4). On the logarithmic scale, models with $M$ had higher $R^{2}$ values, lower RSE and AIC, and were significantly better than the equivalent models without this variable. However, improvements were much smaller than those seen for $\mathrm{CR}$, and residuals were only normalized in two of six models. The coefficients for $M$ were always negative, indicating a strong downwards adjustment for monopodial trees. When back-transformed, the model prediction for monopodial trees is multiplied by $\exp (f \times$ $M)$, which translates to a $21-44 \%$ reduction in the models listed (when $M=0$ then $\exp (f \times M)=1$, indicating no adjustment for trees that are not monopodial). When $M$ was added to models already including $\mathrm{CR}, M$ was no longer significant, except in two instances (Table 4). In these models, the coefficient for $M$ was lower than the equivalent model not including CR, indicating a less severe adjustment for monopodial trees when CR was already considered. None of the other categorical classifications (such as stem irregularity, structural damage, crown quality, or crown illumination index) had a significant effect in any of the models explored.

\section{Practical models for remotely sensed and forestry data}

Five models were created to estimate AGB directly from variables potentially obtainable from remotesensing data ( $H$ and CEA) or simple forest inventories ( $D$ and $H$; Table 5 ). The model including only CEA performed better than the model with $H$ as the only predictor variable, but the model with both variables was best. This model, P.H-CEA, performed reasonably well, but not as well as models with $D$ and $\rho$ (see Table 3). Of the simple inventory models, the model with $H$ (P.D-H) performed better than the model with only $D$ (P.D), but neither performed as well as the model with $H$ and CEA. 
TABLE 4. Extended.

\begin{tabular}{ccccccrr}
\hline \hline$R^{2}$ & RSE & AIC & $F$ & df & $P$ & $\sim \mathrm{N}$ & $P \dagger$ \\
\hline 0.983 & 0.250 & 10.0 & 649 & 4,46 & $<0.001$ & yes & $<0.001$ \\
0.978 & 0.277 & 18.7 & 1050 & 2,48 & $<0.001$ & no & $<0.001$ \\
0.973 & 0.313 & 30.2 & 1748 & 1,49 & $<0.001$ & no & 0.013 \\
0.999 & 0.288 & 18.7 & 13540 & 2,48 & $<0.001$ & yes & $<0.001$ \\
0.999 & 0.300 & 25.9 & 18670 & 1,49 & $<0.001$ & yes & $<0.001$ \\
0.974 & 0.306 & 30.8 & 428 & 4,46 & $<0.001$ & no & 0.042 \\
0.972 & 0.313 & 31.1 & 818 & 2,48 & $<0.001$ & no & 0.011 \\
0.972 & 0.310 & 29.3 & 1693 & 1,49 & $<0.001$ & no & 0.007 \\
0.961 & 0.363 & 46.2 & 584 & 2,48 & $<0.001$ & yes & 0.002 \\
0.958 & 0.372 & 48.9 & 550 & 2,48 & $<0.001$ & yes & 0.005 \\
0.980 & 0.265 & 15.1 & 767 & 3,47 & $<0.001$ & no & 0.023 \\
0.971 & 0.315 & 32.6 & 532 & 3,47 & $<0.001$ & yes & 0.031 \\
\hline
\end{tabular}

\section{Evaluation of all new models}

Finally, we evaluated how well the 27 new equations developed in this study estimated AGB on the original scale $(\mathrm{Mg}$; Table 6). Results were similar to model evaluation on the log-transformed scale, and new models generally estimated AGB of our trees better than published models with the same variables even when CR was not included (Tables 2 and 6). Furthermore, estimates were much more stable than the range of estimates derived from published models. Using $H$ in models tended to increase model precision but consistently lowered estimates, and $H$ did not explain variation in $\mathrm{AGB}$ as well as $\mathrm{CR}$. Including $\mathrm{CR}$ greatly improved estimates, especially of the largest trees, but the monopodial variable was less successful.

Overall, models I.1 CR and II.1 CR performed best. Numerically, CR improved estimates because it reduced the absolute value of errors, compared to equivalent models without CR (Fig. 5). This was true for trees of all sizes, but the magnitude of improvements were especially important in the largest trees.

The three models designed to estimate AGB from tree measurements obtainable from remote-sensing data $(H$ and CEA) performed moderately well (Table 6). The model with both variables (P.H-CEA) was best, but models with only $H$ and CEA substantially overestimated AGB, especially the model with only CEA. Including CEA in models had a similar effect to that of CR: Errors were brought closer to zero compared to the model with only $H$. For most individuals, CEA was more effective than $D$ at reducing errors. However, in all these models, errors were still substantial, especially for the largest trees.

Recommended equations are listed here, according to the inventory or remotely sensed data available. AGB is measured in $\mathrm{kg}$ dry mass, $D$ in $\mathrm{cm}, H$ and $\mathrm{CR}$ in m, CEA in $\mathrm{m}^{2}$, and $\rho$ in $\mathrm{g} / \mathrm{cm}^{3}$, and correction factors have been incorporated.

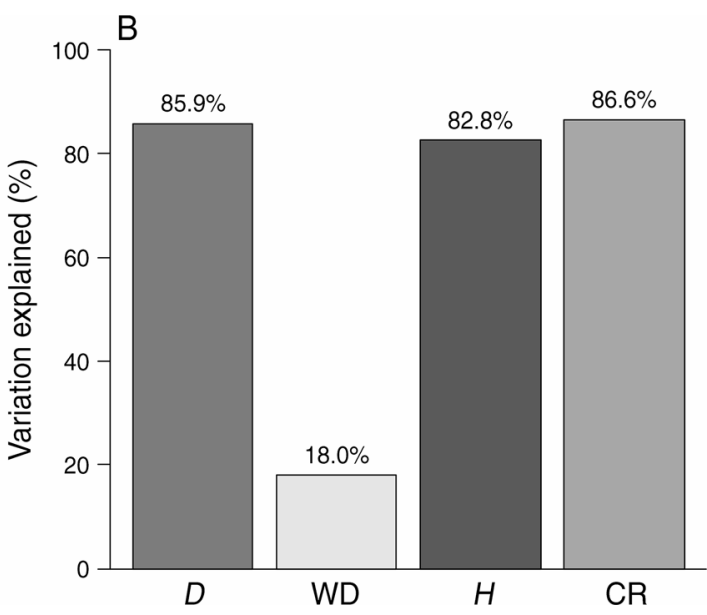

FIG. 4. (A) Variation in aboveground biomass (AGB) explained marginally by each component in the log-transformed model including all four continuous variables: $\ln (\mathrm{AGB})=a+b \ln (D)+c \ln (\mathrm{WD})+d \ln (H)+f \ln (\mathrm{CR})+\varepsilon$. Percentage variation was determined as (Type III sum squares) ${ }_{i}$ (total sum squares) $\times 100 \%$, where $i=$ intercept, diameter $(D)$, wood density (WD), total height $(H)$, average crown radius (CR), and $\varepsilon$ (residual). (B) Variation in AGB explained by each component $\left(R^{2}\right)$ in four separate log-transformed simple linear models. 
TABLE 5. All models including total height $(H ; \mathrm{m})$, crown ellipse area $\left(\mathrm{CEA} ; \mathrm{m}^{2}\right)$, and/or diameter $(D ; \mathrm{cm})$ to predict aboveground biomass (AGB; kg dry mass) created from 51 trees with the diameter range $11-169 \mathrm{~cm}$.

\begin{tabular}{|c|c|c|c|c|c|c|c|c|c|c|c|}
\hline Code & Form & $a$ & $b$ & $c$ & $R^{2}$ & RSE & AIC & $F$ & df & $P$ & $\sim \mathrm{N}$ \\
\hline P.H & $\ln (\mathrm{AGB})=$ & -8.2985 & 4.8114 & & 0.828 & 0.760 & 120.7 & 237 & 1,49 & $<0.001$ & ye \\
\hline P.CEA & $\ln (\mathrm{AGB})=a+c \ln (\mathrm{CEA})$ & 1.0933 & & 1.4064 & 0.866 & 0.672 & 108.2 & 316 & 1,49 & $<0.001$ & yes \\
\hline P.H-CEA & $\ln (\mathrm{AGB})=a+b \ln (H)+c \ln (\mathrm{CEA}$ & -4.3316 & 2.4118 & 0.8490 & 0.938 & 0.462 & 70.9 & 362 & 2,48 & $<0.001$ & yes \\
\hline P.D & $\ln (\mathrm{AGB})=a+b \ln (D)$ & -2.3713 & 2.5154 & $\cdots$ & 0.859 & 0.688 & 110.6 & 299 & 1,49 & $<0.001$ & no \\
\hline P.D-H & $\ln (\mathrm{AGB})=a+b \ln (D)+c \ln (\mathrm{H})$ & -5.9754 & 1.5022 & 2.2988 & 0.909 & 0.559 & 90.4 & 240 & 2,48 & $<0.001$ & no \\
\hline
\end{tabular}

Notes: RSE is residual standard error; $\mathrm{df}$ are degrees of freedom (model, error); and $\sim \mathrm{N}$ indicates whether residuals are distributed normally using the Anderson-Darling normality test $(P \geq 0.05)$. Ellipses indicate that no corresponding parameter is included in the model.

When CR is available, model I.1 CR:

$$
\begin{aligned}
\mathrm{AGB}=\exp ( & -1.8421+1.4378 \ln (D)+0.9379 \ln (H) \\
& +1.0678 \ln (\rho)+0.7624 \ln (\mathrm{CR}))
\end{aligned}
$$

When $H$ is available, model I.1:

$$
\begin{aligned}
\mathrm{AGB}=\exp ( & -2.6009+2.02121 \ln (D)+0.9302 \ln (H) \\
& +1.3257 \ln (\rho))
\end{aligned}
$$

When $H$ is not available, model II.1:

$$
\mathrm{AGB}=\exp (-0.9563+2.4186 \ln (D)+1.5241 \ln (\rho))
$$

When $H$ and CEA are available, model P.H-CEA:

$$
\begin{aligned}
\mathrm{AGB}=\exp ( & -4.2248+2.4118 \ln (H) \\
& +0.8490 \ln (\mathrm{CEA}))
\end{aligned}
$$

\section{DisCUSSION}

\section{Biomass and allometric relationships}

Destructive biomass harvest data sets from tropical

\begin{tabular}{|c|c|c|c|c|c|c|c|}
\hline \multirow[b]{2}{*}{ Name } & \multirow[b]{2}{*}{ Form } & \multicolumn{4}{|c|}{ Error $(\mathrm{Mg})$} & \multicolumn{2}{|c|}{ Rel. Err. (\%) } \\
\hline & & Sum & Mean & SD & $R^{2}$ & Mean & SD \\
\hline P.D & $D$ & -3 & -0.06 & 7.8 & 0.65 & 70 & 179 \\
\hline II.1 & $D+\rho$ & -5 & -0.09 & 4.5 & 0.88 & 13 & 46 \\
\hline II. 5 & $D+1 \rho$ & -33 & -0.64 & 5.4 & 0.83 & 19 & 62 \\
\hline II.3 & $D^{2}+1 \rho$ & -32 & -0.62 & 5.4 & 0.83 & 10 & 54 \\
\hline Mean of all models with $D$ and $\rho$ & & -23 & -0.45 & 5.1 & 0.85 & 14 & 54 \\
\hline P.D-H & $D+H$ & -28 & -0.55 & 6.9 & 0.72 & 43 & 145 \\
\hline I.1 & $\boldsymbol{D}+\boldsymbol{\rho}+\boldsymbol{H}$ & -17 & -0.34 & 4.3 & 0.89 & 11 & 43 \\
\hline I. 3 & $\rho D^{2} H$ & -25 & -0.48 & 4.7 & 0.87 & 13 & 53 \\
\hline I.5 & $1 \rho D^{2} H$ & -40 & -0.78 & 5.0 & 0.85 & 13 & 54 \\
\hline Mean of all models with $D, \rho$, and $H$ & & -27 & -0.54 & 4.6 & 0.87 & 12 & 50 \\
\hline II.1 CR & $\boldsymbol{D}+\boldsymbol{\rho}+\mathbf{C R}$ & $-\mathbf{3}$ & -0.05 & 3.1 & 0.94 & 9 & 32 \\
\hline I.1 CR & $\boldsymbol{D}+\boldsymbol{\rho}+\boldsymbol{H}+\mathbf{C R}$ & -8 & -0.16 & 3.2 & 0.94 & 6 & 28 \\
\hline II. $3 / 5 \mathrm{CR}$ & $D+1 \rho+\mathrm{CR}$ & -12 & -0.24 & 3.3 & 0.93 & 10 & 34 \\
\hline I. $3 \mathrm{CR}$ & $\rho D^{2} H+\mathrm{CR}$ & -14 & -0.27 & 3.8 & 0.92 & 8 & 36 \\
\hline I. $5 \mathrm{CR}$ & $1 \rho D^{2} H+\mathrm{CR}$ & 4 & 0.08 & 4.0 & 0.91 & 11 & 46 \\
\hline Mean of all models with $\mathrm{CR}$ & & -7 & $-\mathbf{0 . 1 3}$ & 3.5 & 0.93 & 9 & 35 \\
\hline I.1 M & $\boldsymbol{D}+\boldsymbol{\rho}+\boldsymbol{H}+\boldsymbol{M}$ & -22 & -0.43 & 4.5 & 0.88 & 10 & 39 \\
\hline $\mathrm{I} .5 \mathrm{M}$ & $1 \rho D^{2} H+M$ & -23 & -0.44 & 4.7 & 0.87 & 11 & 44 \\
\hline I. $3 \mathrm{M}$ & $\rho D^{2} H+M$ & -28 & -0.55 & 4.9 & 0.86 & 11 & 44 \\
\hline II. $5 \mathrm{M}$ & $D+1 \rho+M$ & -30 & -0.59 & 5.4 & 0.83 & 18 & 53 \\
\hline II. $3 \mathrm{M}$ & $D^{2}+1 \rho+M$ & 9 & 0.18 & 5.5 & 0.82 & 14 & 47 \\
\hline Mean of all models with $M$ & & -19 & -0.37 & 5.0 & 0.85 & 13 & 45 \\
\hline I. 3 CR.M & $\rho D^{2} H+\mathrm{CR}+M$ & -17 & -0.34 & 4.0 & 0.91 & 7 & 32 \\
\hline II.3 CR.M & $D+1 \rho+\mathrm{CR}+M$ & -438 & -8.58 & 13.0 & -0.42 & -91 & 14 \\
\hline Mean of all models with $C R$ and $M$ & & -228 & -4.46 & 8.5 & 0.24 & -42 & 23 \\
\hline P.H-CEA & $\boldsymbol{H}+\mathbf{C E A}$ & 17 & 0.34 & 6.1 & 0.78 & 23 & 55 \\
\hline P.CEA & CEA & 68 & 1.33 & 6.6 & 0.73 & 55 & 113 \\
\hline P.H & $H$ & 21 & 0.42 & 10.2 & 0.39 & 86 & 238 \\
\hline Mean of all models with $H$ and CEA & & 35 & 0.69 & 7.6 & 0.63 & 55 & 135 \\
\hline
\end{tabular}
forests are relatively rare and not distributed evenly across tropical forest regions (Clark and Kellner 2012). This new data set consists of AGB of 51 trees from a previously unrepresented geographic region (southwest-

TABLE 6. Summary of errors (sum, mean, standard deviation [SD], and coefficient of correlation $\left[R^{2}\right]$ ) and relative error (Rel. Err.; mean and SD) for each new equation created in this study.

Notes: In model form, numbers refer to the coefficient being constrained to that value ( 1 or $8 / 3)$. Models are arranged from highest to lowest $R^{2}$ among all equations with the same explanatory variables. Numbers in boldface type indicate the "best" (highest $R^{2}$ or lowest absolute value of all other criteria) within each group of equations; and the corresponding model information is also in boldface. 

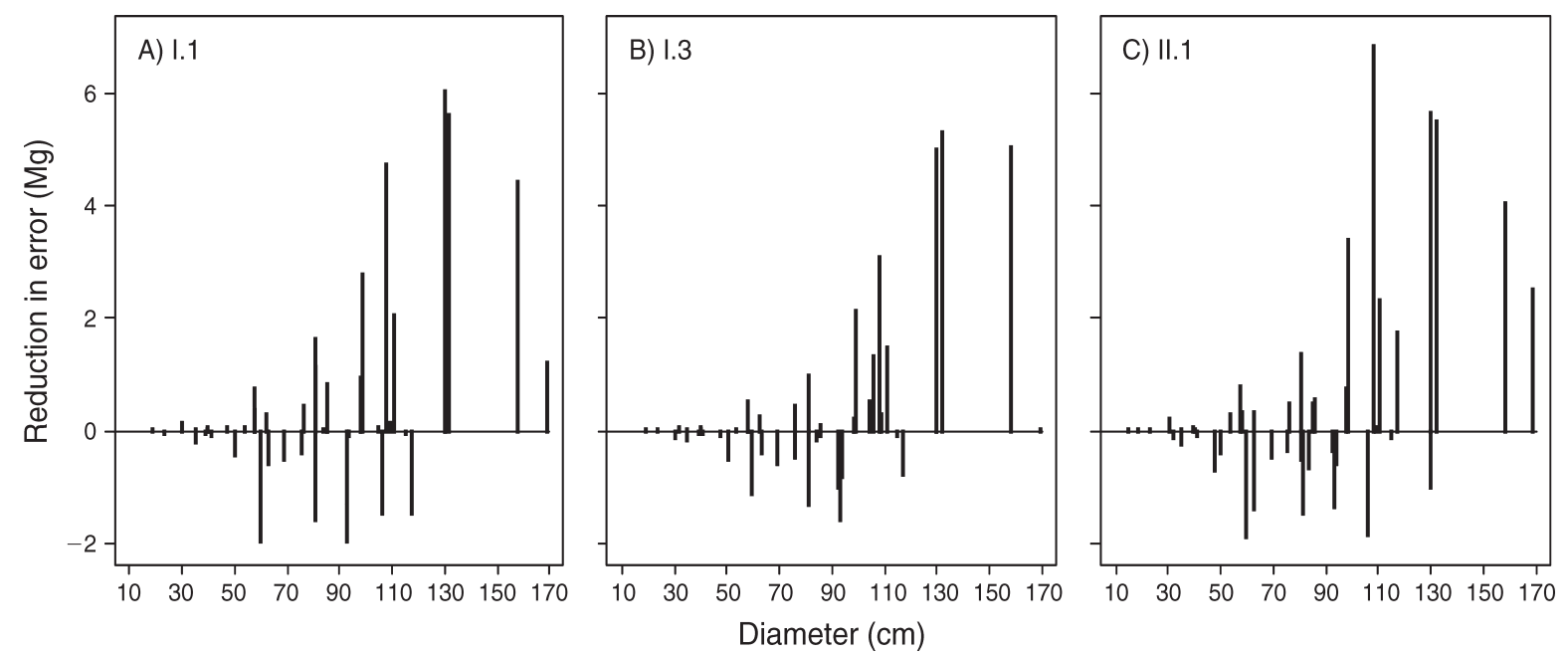

FIG. 5. Improvements in aboveground biomass estimates in comparable models with and without crown radius (CR): Reduction in error was calculated as |error without CR $\mid$ - |error with CR $\mid$ for each tree in our data set. Negative values indicate that the model CR did not improve the estimate. Models are (A) I.1 and I.1 CR, (B) I.3 and I.3 CR, and (C) II.1 and II.1 CR, listed without and with CR, respectively. See Table 2 for clarification of the study abbreviations. Models with constrained coefficients are not shown.

ern Amazonia) and country (Peru), each of which represent large and important areas for forest management and carbon storage. It contains trees across a broad range of diameters (11-169 $\mathrm{cm}$ ) including 12 individuals with $D>100 \mathrm{~cm}$, nearly doubling the number of very-large-tree data available in the entire tropical database (14 trees in Chave et al. 2005 and 17 in Feldpausch et al. 2012). This presents a unique opportunity to test how well pantropical and regional equations estimate AGB of trees from a distant locale and across a broad range of size classes. Our data often show different results than obtained from other studies, which may be predominately influenced by our sampling scheme that most notably includes many very large trees.

The enormous sum of errors (Table 2) exemplifies the need to improve AGB estimates, especially for large trees. The sum of errors in just 51 trees ranged from $-438 \mathrm{Mg}$ to $+329 \mathrm{Mg}$ from both published and new equations, with the most extreme values exceeding total per-hectare AGB density estimates in this area (Cummings et al. 2002, Baker et al. 2004, Salimon et al. 2011). Although our data set does not a represent an actual forest stand, the importance of just one large tree in this environment is clear. AGB density of neighboring forests in Acre, Brazil, has recently been estimated at $224 \pm 50 \mathrm{Mg} /$ ha (Salimon et al. 2011), in which case, the most massive tree in our data set $(76 \mathrm{Mg}$; Goodman et al. 2012) would represent over one-third of this. Several other studies have also found that large trees contribute substantially to AGB density estimates and uncertainty (Brown et al. 1995, Clark and Clark 2000, Baker et al. 2004, Chave et al. 2004). Clearly, more accurate determination of large-tree biomass is required for better mapping and, especially, monitoring of tropical forest biomass and carbon stocks.

Additionally, the importance of representing new geographic regions and forest structures should not be understated. Uncertainty in $\mathrm{C}$ emission estimates is high in the "arc of deforestation" (which spans southern Brazil and northern Bolivia and may extend into southern Peru) largely because of the lack of data in these forest types (Fearnside et al. 2009). A better understanding of this area will also have important implications for national $\mathrm{C}$ budgets (Fearnside et al. 2009), and our results suggest that these forests hold more biomass than reported in recent studies (Nogueira et al. 2008a, b, Feldpausch et al. 2012), especially because large trees, which are prevalent here, may be more massive than previously estimated.

This data set may also be the first to sample trees with approximately equal numbers across all diameter size classes with mean wood density in each size class constrained to be approximately equal to that of the forest. The trees sampled in our data set had mean $\rho$ very close to the stand-level mean (Table 1), though it should be noted that the values deduced from the inventory were only first-order estimates to serve as a guide and cannot be considered entirely reliable. Fortunately, mean $\rho$ of our largest size class $(D \geq 110$ $\mathrm{cm})$ was nearly identical to that of the forest. Therefore, our findings that published equations consistently underestimate $\mathrm{AGB}$ of the largest trees should not be due to sampling bias toward atypically dense trees.

As hypothesized, our trees had a greater proportion of crown mass $(44 \% \pm 2 \%)$ than other Amazonian trees, reported as $31 \%$ (da Silva 2007) and 34\% (Higuchi et al. 1998) in the dense forests of central Amazonia, and 39\% in trees of the open forests of southern Amazonia (da 
Silva 2007, Nogueira et al. 2008a). Thus, accurately accounting for variation in the relative contribution of crown mass may be important for understanding how total AGB relates to tree height and how this relationship differs geographically. For example, Chambers et al. (2001) contended that, although crown proportions varied between central and southern Amazonia, total crown mass was invariant and that trees in the south weigh less due to shorter stems; and Nogueira et al. (2008b) assumed that the proportion of crown mass did not change with tree height. However, comparing our data to published data shows that both the proportion of crown mass and total mass did vary between these regions. To further explore this issue, we estimated crown mass from $D$ of our trees using crownspecific equations reported for both central (Chambers et al. 2001) and southern (Nogueira et al. 2008a) Amazonia and found that these equations substantially underestimated crown mass at our southwestern site. In both cases, underestimates in crown mass explained most (Chambers et al. 2001) or all (Nogueira et al. $2008 a$ ) of the whole-tree biomass underestimates produced by these equations (Table 2). Thus, correctly estimating crown mass may be an essential component of achieving accurate estimates of total AGB.

\section{Evaluating existing models}

We estimated AGB of our trees from 38 published pantropical and Amazonian equations to test how well these models predict biomass in a previously unrepresented region. As hypothesized, many models generated from other areas produced large errors when estimating AGB of our trees. Estimates were particularly poor for very large trees, and models including $H$ often produced substantial underestimates. We examined outcomes from models using different input variables $(D, D$ and $\rho$, and $D, \rho$, and $H$; Table 2) with special attention paid to studies that have lowered AGB estimates for the southwestern Amazonian forests due to lower tree heights. Because accuracy, or total AGB, is required for global carbon budget estimates (Clark and Kellner 2012), we put more emphasis on true, rather than relative, errors.

Our data suggest that AGB estimates from published models that include $H$ are too low because proportionally greater crown mass at least partially compensates for shorter tree stature in our study area. Several models without $H$ overestimated AGB, but nearly all models that include $H$ underestimated AGB substantially (Table 2). However, the recent reductions in AGB estimates due to lower tree heights appear to be too extreme compared to our data, especially for large trees (Fig. 3). In the first instance, the downward adjustments in total AGB estimates by Nogueira et al. (2008b) due to $H$ was less than reported: $5.5 \%$ reduction using our measured $D$ and estimated $H$ (mean ${ }_{\mathrm{E}}=-5.5 \%$ if the Higuchi estimates were considered accurate) vs. $6 \%$ or $11 \%$ reduction reported in Nogueira et al. (2008b). The
Feld 1 model $(D$ and $\rho$ ) resulted in an overall $6 \%$ overestimate of AGB, but the Feld 2 model $\left(\rho D^{2} H\right)$ underestimated AGB by $14 \%$. The same pattern was also seen in the two models recommended by Chave et al. (2005) for moist tropical forests: Ch II.3 ( $D$ and $\rho$ ) overestimated total AGB by $4 \%$ in all 51 trees, but model Ch I.5 $\left(\rho D^{2} H\right)$ underestimated AGB by $11 \%$. The difference in these two pairs (19\% or $15 \%)$ is comparable to the reduction in AGB recently reported for the western Amazon (16\%; Feldpausch et al. 2012), but our data show that it is not accurate to conclude that this difference is due to overestimates caused by not including $H$. Rather, a majority of the difference was due to underestimates from models that did include $H$.

To further test the effect of using estimated $H$ as an explanatory variable, we calculated AGB from three of our models with estimated $H$ values obtained from the $H-D$ equation developed in this study (see section Results: Biomass and allometric relationships). We found that this method did not work well with our data. Predictions made from our models I.1, I.3, and I.5 using $D, \rho$, and estimated $H$ were generally not as good as those from the best equation that did not include $H$ at all (II.1), even though $H$ was estimated from a $H-D$ relationship developed from the same 51 trees. Several other authors have also warned against including tree height in regression equations (Lescure et al. 1983, Overman et al. 1994, Chave et al. 2001, Leuschner et al. 2007). For example, it may systematically increase correlation coefficients, over equations using $D$ only, even when $H$ is poorly measured (Chave et al. 2001).

We attribute poor estimates from published models, especially the underestimates in models including $H$, to the architectural differences between the trees in our area vs. other regions represented in Amazonian and pantropical data sets. It has recently been shown that maximum height and $H-D$ relationships are lower in South America than in Asia and Africa (Feldpausch et al. 2011, Banin et al. 2012), and within Amazonia, trees in the south are shorter than those in the northeast (Nogueira et al. 2008b, Feldpausch et al. 2011). We propose that this is likely to be a result from the tradeoff between vertical height growth and horizontal crown growth to maximize light capture (King 1996, Aiba and Kohyama 1997, Sterck and Bongers 1998, Bohlman et al. 2008). This, in turn, suggests that models with only $D$ and $\rho$ may be more universal than models with $D, \rho$, and $H$. Indeed, many studies across the tropics have found that trees with greater adult stature and more slender stem allometry are also associated with narrower crowns (Poorter et al. 2003, Bohlman and O'Brien 2006, King et al. 2006, Poorter et al. 2006, Aiba and Nakashizuka 2009, Iida et al. 2012). This concurs with our hypothesis that, although our trees are shorter (Nogueira et al. $2008 b$, Feldpausch et al. 2011), they tend to have larger crowns relative to trees in other areas, especially compared to regions that have been well represented in the pantropical biomass data set (i.e., Southeast Asia 
and central and eastern Amazonia). Vegetation height itself may be influenced by forest structure, whereby the presence of tall, dominant trees, especially in Asia, may drive other canopy trees to grow tall (Banin et al. 2012). In contrast, the large crowns in our forest may be related to the slightly fragmented canopy, which provides no incentive for height growth after becoming emergent but does allow branches to expand horizontally.

Crown variation may also explain why neither of the equations from the geographically closest studies, southern Amazonia (Nogueira et al. 2008a) and northwestern Amazonia (Alvarez et al. 2012), consistently estimated AGB of our trees well. Although Colombia, Ecuador, and Peru are often grouped together as the western Amazon, it has been suggested that there is a north-south gradient in crown size, from Colombia to Peru, paralleling a gradient of increasing moisture seasonality (Barbier et al. 2010). Likewise, there may be greater variation in crown sizes in the forests of the southern Amazon than in the southwest (Barbier et al. 2010). More directly measured data on crown dimensions are needed to confirm these patterns.

Several studies have proposed that equations that lack $H$ will tend to overestimate AGB of trees with $D$ outside of the range used to create these models (Chambers et al. 2001, Zianis and Mencuccini 2004, Chave et al. 2005, Vieilledent et al. 2012). One of the reasons stated, which is also the rationale for the polynomial- $D$ model form, is that crown and stem structural damage increase with tree size (Chambers et al. 2001), especially in the southern and southwestern Amazonian forests (Nogueira et al. 2008b). The severity and frequency of irregularities and hollow trunks have also been reported to increase as tree size increases (Zimmerman et al. 1994, Fearnside 1997, Clark and Clark 2000, Chambers et al. 2001, Nogueira et al. 2006). However, the current data set includes several very large trees with diameters outside the range of nearly all the published equations evaluated. We found that empirical published equations both over- and underestimated AGB of individual large trees, but, on average, they underestimated AGB of the largest trees (Table 2, Fig. 3). Furthermore, we observed very little crown or structural damage in our forest type due to bamboo, lianas, or any other natural influence. In fact, structural damage in the crown was only observed in 4 of 51 trees, with $>10 \%$ estimated loss only seen in one tree. In a regression analysis, neither crown nor stem structural damage was related to tree size, nor did they significantly reduce biomass in our models. The rarity of substantial structural damage may be one of the reasons why all published models with the negative cubic term for $D$ severely underestimated AGB of our trees and why no more than one term for $D$ was ever significant in our models.

In addition to the natural variation found in large trees, the poor estimates for large tree biomass may be a result of sampling schemes, data analysis, and model selection, all of which have allowed considerable errors for large trees to remain. First, all data sets examined have sampled a great proportion of small trees, often for good reasons, and then data are log-transformed for analysis. Both these factors reduce the influence of large trees in regression analysis, and the resulting models can have very different shapes and regression coefficients depending on the few large tree data included (Higuchi et al. 1998, Nelson et al. 1999). Second, basing model selection on relative error criteria will tend to weight improvements for small tree biomass fits equally to improvements in the fits of large trees. However, our results show that very different conclusions about "best" models can be derived from criteria based on true and relative errors. In both pantropical and Amazonian model AGB predictions, mean ${ }_{\mathrm{RE}}$ was almost always positive, but mean $_{\mathrm{E}}$ was more often negative because AGB for most of our trees with $D<70 \mathrm{~cm}(n=25)$ was overestimated, while AGB of many large trees was severely underestimated. Thus, evaluating only relative error can lead to different conclusions about model performance than evaluating true error on models created from equal samples sizes in each $D$ size class.

\section{New models using diameter, wood density, height, and crown dimensions}

To our knowledge, this is the first study to have explicitly examined the effect of crown size and architectural type on measured tropical tree biomass. As hypothesized, the new models presented here show that incorporating crown size or structure into allometric equations can capture variation in tree biomass not explained statistically by $D$, $\rho$, or $H$ (Fig. 4A), because it helps account for the contribution of crown mass to total tree AGB. CR explains more variation in AGB than any other single variable (Fig. 4B) and marginally explains more variation than $H$ in the full model with all four variables (Fig. 4A). In models with multiple variables, including $\mathrm{CR}$, reduced estimate errors in trees of all sizes, but the magnitude of its effect was most notable in the largest trees (Fig. 5), whose biomass has been notoriously difficult to predict. For example, in a large pantropical data set, errors for small trees could be reduced by including $H$ in models, but errors for large trees remained (Feldpausch et al. 2012). In our analysis, we found the same effects of $H$ as Feldpausch et al. (2012), whereas CR was effective at reducing error for all tree sizes. Thus, we suggest that this parameter should be included in allometric equations when higher accuracy of AGB estimates is desired.

Using local data, including CR greatly improved model estimates, even more so than $H$, and it may not be necessary to include $H$ when $\mathrm{CR}$ is already included. This is apparently in contrast to expectations that both $H$ and CR would be needed to account for trade-offs between vertical height and horizontal branch growth (King et al. 2006, Poorter et al. 2006, Iida et al. 2012). However, including both $H$ and CR may be necessary to account for architectural variation and accurately assess 
$\mathrm{AGB}$, if comparing different geographical regions or attempting to create widely applicable allometric equations. For example, AGB of trees in northwestern Amazonia were overestimated by Chave et al. (2005) models without $H$ (Alvarez et al. 2012), where trees may have smaller crowns than in southwestern Amazonia (Barbier et al. 2010). The relationship between maximum height, $H-D$ ratios, and crown size may also change with tree development and geography. In a Liberian forest, crown width and depth were negatively correlated with adult stature in trees throughout their ontogeny (Poorter et al. 2003). However, in Bolivia, the same negative relationship was observed in young trees only, and the relationship became positive in adult trees (Poorter et al. 2006). This reinforces the view that accounting for CR may always be important in both local and pantropical models and suggests that, like $H$, the relationship between $\mathrm{CR}$ and $\mathrm{AGB}$ may not be consistent across all forest types or tree sizes. Tropical forest biomass estimates could be improved by more research on crown dimensions and allometry.

Of all models not including crown factors, those developed in this study better estimated AGB of trees than published models with the same variables. Predictions from new equations (Table 6) are also far more stable than those from published studies, in which models created from the same data set have yielded very different results when estimating AGB of our trees (Table 2). This may be a result of our sampling scheme, which has a fairly even $D$ distribution and includes several large trees, as was also observed in another data set with a similar design (Overman et al. 1994).

Another key difference between the new and published models is the importance and influence of wood density. In published equations, the coefficient for $\rho$ is always $<1$ and sometimes very low $(<0.5)$. However, in our new models, this coefficient is always $>1$, and equations without the coefficient constrained to 1 always performed better. Thus, our data suggests that $\rho$ plays a more important role in allometry and total AGB than merely converting volume to mass. It may be correlated to other, unmeasured variables related to ecological strategy, tree architecture, and mechanics (King et al. 2006, Anten and Schieving 2010, Iida et al. 2012). Specifically, $\rho$ has been positively correlated with crown width (Sterck et al. 2006, Anten and Schieving 2010, Iida et al. 2012) and related to variation between height and crown width with diameter (King et al. 2006). In this data set, we also found that $\rho$ was significantly and positively related to $\mathrm{CR}$. In our regression analysis, this idea is further supported by the reduction in the coefficient for $\rho$ when $\mathrm{CR}$ or $M$ was included. Our sampling design, with a wide range of $\mathrm{AGB}$ and $\rho$ in every $D$ size class, may have allowed the influence of this variable to be expressed statistically. The importance of $\rho$ is also clear in the ANOVA, in which $\rho$ explained more variation in tree biomass than any other variable, when all other variables and interactions are already included in the model (31.2\%; Fig. 4A), even though, as a lone variable, $\rho$ explains the least variation in total AGB (18\%; Fig. 4B). This is likely an effect of multicollinearity between the other three variables $(D, H$, and $\mathrm{CR}$ ), while the effect of $\rho$ is more independent and explains additional variation in AGB after structural effects are considered. For example, AGB of two large trees of comparable size, one species with low $\rho$ and one with high $\rho$, can vary by over an order of magnitude (Goodman et al. 2012). Though we did not explicitly study species effects, our results are consistent with recent findings that allometric relationships are highly affected by species (Lines et al. 2012). Thus, wood density, an intrinsic property, appears to largely explain variation among species after accounting for superficially measured size variables.

Including CR also helps resolve many of the statistical problems associated with current allometric equations, as it reduced error for all tree sizes and normalized distribution of the error. Conversely, non-normal error distributions call into question the validity of equations not including CR. However, our models, even without $\mathrm{CR}$, were generally better estimators of AGB than published models, demonstrating that the accuracy of our models has not been undermined. In our analysis, non-normal distributions were usually caused by a slight negative tail, often caused by the largest $D$ tree in our data set $(169 \mathrm{~cm})$, confirming that irregularly shaped boles can cause very large errors in biomass estimates (Clark and Clark 2000, Clark 2002, Nogueira et al. 2006). For this tree, $D$ was measured over a highly fluted stem, as specified by standard protocols when the entire stem is fluted; e.g., RAINFOR (Phillips et al. 2009) and Winrock International (Pearson et al. 2005). Thus, actual basal area was lower than indicated by measured $D$. Nonetheless, we chose to keep this tree in the data set because it was selected via our unbiased methodology and, thus, represents true variability in the relationship found between $D$ and AGB. As recently highlighted, it is important not to bias allometric equations by excluding "imperfect" trees in biomass data (Clark and Kellner 2012).

Although including $\mathrm{CR}$ in allometric equations greatly improves AGB estimates, collecting crown dimension data can be an expensive and time-consuming task. Thus, we realize that it will most likely not become part of extensive forest inventories. Nonetheless, the problem posed by errors in large trees makes it important to determine the value of $D$ at which the gains in accuracy merit measuring CR. Examining improvements in our data set, it appears that CR should be measured and used to estimate AGB of all trees $D \geq$ $95 \mathrm{~cm}$, as it consistently and greatly improves estimates of these trees (Fig. 5).

The monopodial variable $(M)$ was not as effective as $\mathrm{CR}$, but the significance of this variable shows that a simple architectural classification system has the potential to improve AGB estimates without labor-intensive 
data collection. The lower biomass of monopodial trees also demonstrates that crown form, or how branches fill space, may be important, as well as the peripheral dimensions. Equations with both $\mathrm{CR}$ and $M$ performed very poorly, suggesting these two parameters covary, and theoretical work has also noted that total branch length is lesser in monopodial trees than trees with other growth patterns (Mäkelä and Valentine 2006). In the current data set, only 11 trees were classified as having monopodial architecture. Hence, a larger sample size may help improve the performance of this architectural variable in future models.

The lack of significant influence of crown position (illumination index) was somewhat surprising, even when separated into binomial variables: emergent/not emergent or suppressed/not suppressed. We expected that crowns of emergent trees would be much larger (cf., King 1996, Thomas 1996, Poorter et al. 2006), and thus change the relationship between $D, \rho$, and $H$ and AGB. Again, the lack of significant effects may be due to the small sample size in this data set, and more samples could help improve our understanding of the relationship between forest structure, individual tree allometry, and biomass. We suggest that new biomass studies should attempt to include these factors, as well as crown architectural classification (even applied retrospectively) and, most importantly, crown dimensions.

\section{Practical models for remotely sensed and forestry data}

Models designed to allow AGB to be inferred from LiDAR or other remote-sensing data, using only $H$ and CEA, were relatively successful considering that they exclude the two variables usually regarded as the most important, $D$ and $\rho$ (e.g., Baker et al. 2004). Including crown area (CEA) in models greatly improved estimates over models with only $H$. The model including both $H$ and CEA actually performs better than the equation with $H$ and $D$, probably because CEA is both related to $D$ and acts as a weak proxy to $\rho$. Indeed, $\rho$ was significantly linearly related to CEA $\left(R^{2}=0.068, P=\right.$ $0.036)$, but not significantly related to $D\left(R^{2}=0.034, P=\right.$ 0.193). This further demonstrates the importance of crown dimensions and the potential to improve AGB estimates from remote sensing. Estimating CEA from LiDAR data may be restricted practically to emergent trees, but, as illustrated earlier, more accurately estimating AGB of the largest trees will improve AGB density estimates greatly. Furthermore, given that the largest trees are most likely to be removed by selective logging or increased mortality (Lindenmayer et al. 2012), applying these methods could help improve estimates of carbon stock changes in degraded and managed forests.

\section{CONCLUSIONS AND IMPLiCATIONS}

Current maps and models of the magnitude, distribution, and sensitivity of tropical forest carbon stocks and fluxes are in part limited by the great challenge of developing robust allometric models to estimate tree biomass. This study shows that including crown dimensions in allometric equations to predict tropical tree biomass can greatly improve estimates, especially for trees with $D>95 \mathrm{~cm}$ (Table 6, Fig. 5), which have long been the cause of much uncertainty in forest biomass estimates and are the focus of widespread degradation via selective logging across the tropics. Tree crowns have been largely ignored both in allometric theory and in practical attempts to improve biomass estimates for the vast regions where little or no directly measured biomass data exist.

By testing published model estimates on new biomass data from a previously unrepresented region (southwestern Amazonia), we show that the majority of published equations were poor predictors of our 51 trees, predominately due to severe underestimates of most of the largest trees. For both the most widely adopted (Chave et al. 2005) and recently proposed new pantropical biomass equations (Feldpausch et al. 2012), models without height slightly overestimated AGB of our trees, but models with height always underestimated AGB by a greater amount (Table 2, Fig. 3). Therefore, adjusting biomass equations for height alone may be insufficient to account for allometric variation between regions and forest types because crown mass must also be considered. In southwestern Amazonia, crowns are relatively large (Fig. 2), which substantially compensate for their lower height. These results also show that the difference in predictions from models with and without height cannot be attributed simply to overestimates of models without height. More generally, "best estimates," even from models with all possible variables, should not be considered as entirely accurate or baselines to which all other estimates are compared.

In new models, crown radius accounts for variation in AGB not explained by diameter, wood density, or height. In fact, crown radius explained more variation and improved model estimates more than height (Fig. 4). Given the apparent geographic variation of crown size across both broad geographical regions and within local scales (Barbier et al. 2010), the inclusion of crown dimensions in allometric equations is likely to be widely important for improving the performance of both pantropical and regional models. Models developed from this data set, which contains several very large trees and includes and crown radius as a parameter, show promise for improving tropical AGB estimates and carbon stock changes via both traditional field inventories and emerging remote-sensing technologies.

\section{ACKNOWLEDGMENTS}

The authors thank the many individuals and institutions that have made this work possible. This project has been financially supported by School of Geography and University of Leeds, World Wildlife Fund (WWF)-Peru, and the Moore Foundation and USDA Forest Service grants to the Amazon Forest Inventory Network (RAINFOR). In-kind support has been provided by Maderacre, Peruvian Amazon Research Institute (IIAP), and WWF in Puerto Maldonado. For their logistical 
support during field work, we extend personal thanks to Ronaldo Pacheco, Nelson Kroll, and Andrea Castagnola at Maderacre, and Sandro Cardozo and Percy at Serfores; Juan Carlos Riveros, Cecilia Alvarez, and especially Nelson Gutierrez at WWF-Peru; and Ronald Corvera and Dennis del Castillo at IIAP. We also thank Simon Lewis at University of Leeds for valuable advice during fieldwork planning and revisions on the manuscript; Naikoa Aguilar, Doug Hall, and Lou Leonard at WWF-USA for intellectual support during the field campaign; and two anonymous reviewers for suggestions to improve the manuscript. We especially thank Cesar Vela, Joel MillwardHopkins, Sebastian Tapia, Ana del Pilar Suimer, and all the field assistants for their extraordinarily hard work during the field campaign. R. C. Goodman was supported by the Fullyfunded International Research Scholarship from University of Leeds during the research. All fieldwork was conducted with permits from the Dirección General Forestal y de Fauna Silvestre, within the Peruvian Ministry of Agriculture, for collection outside of protected areas.

\section{Literature Cited}

Achard, F., H. J. Stibig, H. Eva, and P. Mayaux. 2002. Tropical forest cover monitoring in the humid tropics: TREES project. Tropical Ecology 43:9-20.

Aiba, M., and T. Nakashizuka. 2009. Architectural differences associated with adult stature and wood density in 30 temperate tree species. Functional Ecology 23:265-273.

Aiba, S. I., and T. Kohyama. 1996. Tree species stratification in relation to allometry and demography in a warm-temperate rain forest. Journal of Ecology 84:207-218.

Aiba, S. I., and T. Kohyama. 1997. Crown architecture and lifehistory traits of 14 tree species in a warm-temperate rain forest: significance of spatial heterogeneity. Journal of Ecology 85:611-624.

Alvarez, E., A. Duque, J. Saldarriaga, K. Cabrera, G. de las Salas, I. del Valle, A. Lema, F. Moreno, S. Orrego, and L. Rodríguez. 2012. Tree above-ground biomass allometries for carbon stocks estimation in the natural forests of Colombia. Forest Ecology and Management 267:297-308.

Anten, N. P. R., and F. Schieving. 2010. The role of wood mass density and mechanical constraints in the economy of tree architecture. American Naturalist 175:250-260.

Araújo, T. M., N. Higuchi, and J. A. D. Junior. 1999. Comparison of formulae for biomass content determination in a tropical rain forest site in the state of Para, Brazil. Forest Ecology and Management 117:43-52.

Asner, G. P. 2009. Tropical forest carbon assessment: integrating satellite and airborne mapping approaches. Environmental Research Letters 4:034009.

Asner, G. P. 2011. Painting the world REDD: addressing scientific barriers to monitoring emissions from tropical forests. Environmental Research Letters 6:021002.

Asner, G. P., R. F. Hughes, T. A. Varga, D. E. Knapp, and T. Kennedy-Bowdoin. 2009. Environmental and biotic controls over aboveground biomass throughout a tropical rain forest. Ecosystems 12:261-278.

Asner, G. P., D. E. Knapp, E. N. Broadbent, P. J. C. Oliveira, M. Keller, and J. N. Silva. 2005. Selective logging in the Brazilian Amazon. Science 310:480-482.

Asner, G. P., et al. 2010. High-resolution forest carbon stocks and emissions in the Amazon. Proceedings of the National Academy of Sciences USA 107:16738-16742.

Baccini, A., et al. 2012. Estimated carbon dioxide emissions from tropical deforestation improved by carbon-density maps. Nature Climate Change 2:182-185.

Baker, T. R., et al. 2004. Variation in wood density determines spatial patterns in Amazonian forest biomass. Global Change Biology 10:545-562.

Banin, L., et al. 2012. What controls tropical forest architecture? Testing environmental, structural and floristic drivers. Global Ecology and Biogeography 21:1179-1190.
Barbier, N., P. Couteron, C. Proisy, Y. Malhi, and J. P. Gastellu-Etchegorry. 2010. The variation of apparent crown size and canopy heterogeneity across lowland Amazonian forests. Global Ecology and Biogeography 19:72-84.

Baskerville, G. L. 1972. Use of logarithmic regression in the estimation of plant biomass. Canadian Journal of Forest Research 2:49-53.

Basuki, T. M., P. E. van Laake, A. K. Skidmore, and Y. A. Hussin. 2009. Allometric equations for estimating the aboveground biomass in tropical lowland Dipterocarp forests. Forest Ecology and Management 257:1684-1694.

Bohlman, S. A., W. F. Laurance, S. G. Laurance, H. E. M. Nascimento, P. M. Fearnside, and A. Ana. 2008. Importance of soils, topography and geographic distance in structuring central Amazonian tree communities. Journal of Vegetation Science 19:863-874.

Bohlman, S., and S. O'Brien. 2006. Allometry, adult stature and regeneration requirement of 65 tree species on Barro Colorado Island, Panama. Journal of Tropical Ecology 22:123-136.

Bortolot, Z. J., and R. H. Wynne. 2005. Estimating forest biomass using small footprint LiDAR data: An individual tree-based approach that incorporates training data. ISPRS Journal of Photogrammetry and Remote Sensing 59:342-360.

Brown, I. F., L. A. Martinelli, W. W. Thomas, M. Z. Moreira, C. A. Cid Ferreira, and R. A. Victoria. 1995. Uncertainty in the biomass of Amazonian forests: An example from Rondônia, Brazil. Forest Ecology and Management 75:175189.

Brown, S., A. J. R. Gillespie, and A. E. Lugo. 1989. Biomass estimation methods for tropical forests with applications to forest inventory data Forest Science. 35:881-902.

Cannell, M. G. R. 1984. Woody biomass of forest stands. Forest Ecology and Management 8:299-312.

Chambers, J. Q., J. dos Santos, R. J. Ribeiro, and N. Higuchi. 2001. Tree damage, allometric relationships, and aboveground net primary production in central Amazon forest. Forest Ecology and Management 152:73-84.

Chave, J., et al. 2005. Tree allometry and improved estimation of carbon stocks and balance in tropical forests. Oecologia 145:87-99.

Chave, J., R. Condit, A. Salomon, A. Hernandez, S. Lao, and R. Perez. 2004. Error propagation and scaling for tropical forest biomass estimates. Philosophical Transactions Biological Sciences 359:409-420.

Chave, J., D. Coomes, S. Jansen, S. L. Lewis, N. G. Swenson, and A. E. Zanne. 2009. Towards a worldwide wood economics spectrum. Ecology Letters 12:351-366.

Chave, J., B. Riera, and M. A. Dubois. 2001. Estimation of biomass in a neotropical forest of French Guiana: spatial and temporal variability. Journal of Tropical Ecology 17:79-96.

Clark, D. A. 2002. Are tropical forests an important carbon sink? Reanalysis of the long-term plot data. Ecological Applications 12:3-7.

Clark, D. B., and D. A. Clark. 2000. Landscape-scale variation in forest structure and biomass in a tropical rain forest. Forest Ecology and Management 137:185-198.

Clark, D. B., and J. R. Kellner. 2012. Tropical forest biomass estimation and the fallacy of misplaced concreteness. Journal of Vegetation Science 23:1191-1196.

Clark, D. B., J. M. Read, M. L. Clark, A. M. Cruz, M. F. Dotti, and D. A. Clark. 2004. Application of 1-M and 4-M resolution satellite data to ecological studies of tropical rain forests. Ecological Applications 14:61-74.

Cummings, D. L., J. Boone Kauffman, D. A. Perry, and R. Flint Hughes. 2002. Aboveground biomass and structure of rainforests in the southwestern Brazilian Amazon. Forest Ecology and Management 163:293-307.

da Silva, R. P. 2007. Alometria, estoque e dinâmica da biomassa de florestas primárias e secundárias na região de 
Manaus (AM). Universidade Federal do Amazonas Manaus, Manaus, Brazil.

Dawkins, H. C., and D. R. B. Field. 1978. A Long-term surveillance system for British woodland vegetation. Department of Forestry, Oxford University, Oxford, UK.

Djomo, A. N., A. Ibrahima, J. Saborowski, and G. Gravenhorst. 2010. Allometric equations for biomass estimations in Cameroon and pan moist tropical equations including biomass data from Africa. Forest Ecology and Management 260:1873-1885.

Drake, J. B., R. G. Knox, R. O. Dubayah, D. B. Clark, R. Condit, J. B. Blair, and M. Hofton. 2003. Above-ground biomass estimation in closed canopy Neotropical forests using lidar remote sensing: factors affecting the generality of relationships. Global Ecology and Biogeography 12:147-159.

Ebeling, J., and M. Yasue. 2008. Generating carbon finance through avoided deforestation and its potential to create climatic, conservation and human development benefits. Philosophical Transactions of the Royal Society B 363:1917-1924

Enquist, B. J., G. B. West, E. L. Charnov, and J. H. Brown. 1999. Allometric scaling of production and life-history variation in vascular plants. Nature 401:907-911.

FAO. 2010. Global forest resources assessment 2010. Food and Agriculture Organization of the United Nations, Rome, Italy.

FAO, ISRIC, UNEP, and CIP. 1998. Soil and terrain database for Latin America and the Caribbean (v2.0), 1:5M. scale. Land and Water Digital Media Series 5. FAO, Rome, Italy.

Fearnside, P. M. 1997. Wood density for estimating forest biomass in Brazilian Amazonia. Forest Ecology and Management 90:59-87.

Fearnside, P. M., C. A. Righi, P. M. L. d. A. Graça, E. W. H. Keizer, C. C. Cerri, E. M. Nogueira, and R. I. Barbosa. 2009. Biomass and greenhouse-gas emissions from land-use change in Brazil's Amazonian "arc of deforestation": The states of Mato Grosso and Rondônia. Forest Ecology and Management 258:1968-1978.

Feldpausch, T. R., et al. 2011. Height-diameter allometry of tropical forest trees. Biogeosciences 8:1081-1106.

Feldpausch, T. R., et al. 2012. Tree height integrated into pantropical forest biomass estimates. Biogeosciences 9:33813403.

Goodman, R. C., O. L. Phillips, and T. R. Baker. 2012. Tropical forests: Tightening up on tree carbon estimates. Nature 491:527.

Hallé, F., R. A. A. Oldeman, and P. B. Tomlinson. 1978. Tropical trees and forests: an architectural analysis. SpringerVerlag, Berlin, Germany.

Higuchi, N., J. Santos, R. J. Ribeiro, L. Minette, and Y. Biot. 1998. Biomassa da parte aérea da vegetação da floresta tropical úmida de terra firme da Amazônia brasileira, Biomass of the aboveground vegetation of humid tropical forest on terra firme in the Brazilian Amazon. Acta Amazonica 28:153-166.

Hijmans, R. J., S. E. Cameron, J. L. Parra, P. G. Jones, and A. Jarvis. 2005. Very high resolution interpolated climate surfaces for global land areas. International Journal of Climatology 25:1965-1978.

Houghton, R. A., F. Hall, and S. J. Goetz. 2009. Importance of biomass in the global carbon cycle. Journal of Geophysical Research: Biogeosciences 114:G00E03.

Houghton, R. A., K. T. Lawrence, J. L. Hackler, and S. Brown. 2001. The spatial distribution of forest biomass in the Brazilian Amazon: a comparison of estimates. Global Change Biology 7:731-746.

Iida, Y., L. Poorter, F. J. Sterck, A. R. Kassim, T. Kubo, M. D. Potts, and T. S. Kohyama. 2012. Wood density explains architectural differentiation across 145 co-occurring tropical tree species. Functional Ecology 26:274-282.
Jiménez-Rojas, E. M., A. C. Londoño-Vega, and H. F. M. Vester. 2002. Descripción de la arquitectura de Iryanthera tricornis, Osteophloeum platyspermum y Virola pavonis (Myristicaceae). Caldasia 24:65-94.

Kato, A., L. M. Moskal, P. Schiess, M. E. Swanson, D. Calhoun, and W. Stuetzle. 2009. Capturing tree crown formation through implicit surface reconstruction using airborne lidar data. Remote Sensing of Environment 113:1148-1162.

Keeling, H. C., and O. L. Phillips. 2007. A calibration method for the crown illumination index for assessing forest light environments. Forest Ecology and Management 242:431437.

Ketterings, Q. M., R. Coe, M. van Noordwijk, Y. Ambagau, and C. A. Palm. 2001. Reducing uncertainty in the use of allometric biomass equations for predicting above-ground tree biomass in mixed secondary forests. Forest Ecology and Management 146:199-209.

King, D. A. 1996. Allometry and life history of tropical trees. Journal of Tropical Ecology 12:25-44.

King, D. A., S. J. Davies, S. Tan, and N. S. M. Noor. 2006. The role of wood density and stem support costs in the growth and mortality of tropical trees. Journal of Ecology 94:670 680.

Kitajima, K., S. S. Mulkey, and S. J. Wright. 2005. Variation in crown light utilization characteristics among tropical canopy trees. Annals of Botany 95:535-547.

Lefsky, M. A., W. B. Cohen, G. G. Parker, and D. J. Harding. 2002. Lidar remote sensing for ecosystem studies. Bioscience 52:19-30.

Lescure, J. P., H. Puig, B. Riera, D. Leclerc, A. Beekman, and A. Beneteau. 1983. Phytomass in a tropical rain-forest of French Guiana. Acta Oecologica 4:237-251.

Leuschner, C., G. Moser, C. Bertsch, M. Roderstein, and D. Hertel. 2007. Large altitudinal increase in tree root/shoot ratio in tropical mountain forests of Ecuador. Basic and Applied Ecology 8:219-230.

Lindenmayer, D. B., W. F. Laurance, and J. F. Franklin. 2012. Global decline in large old trees. Science 338:1305-1306.

Lines, E. R., M. A. Zavala, D. W. Purves, and D. A. Coomes. 2012. Predictable changes in aboveground allometry of trees along gradients of temperature, aridity and competition. Global Ecology and Biogeography 21:1017-1028.

Maderacre. 2009. Compendio: Resumen publico de monitoreo y evaluaciones. Maderacre, Iñapari, Peru.

Mäkelä, A., and H. T. Valentine. 2006. Crown ratio influences allometric scaling in trees. Ecology 87:2967-2972.

Mascaro, J., C. M. Litton, R. F. Hughes, A. Uowolo, and S. A. Schnitzer. 2011. Minimizing bias in biomass allometry: model selection and log-transformation of data. Biotropica 43:649653.

Morsdorf, F., E. Meier, B. Kötz, K. I. Itten, M. Dobbertin, and B. Allgöwer. 2004. LIDAR-based geometric reconstruction of boreal type forest stands at single tree level for forest and wildland fire management. Remote Sensing of Environment 92:353-362.

Nelson, B. W., R. Mesquita, J. L. G. Pereira, S. G. A. de Souza, G. T. Batista, and L. B. Couto. 1999. Allometric regressions for improved estimate of secondary forest biomass in the central Amazon. Forest Ecology and Management 117:149 167.

Nogueira, E. M., P. M. Fearnside, B. W. Nelson, R. I. Barbosa, and E. W. H. Keizer. 2008a. Estimates of forest biomass in the Brazilian Amazon: New allometric equations and adjustments to biomass from wood-volume inventories. Forest Ecology and Management 256:1853-1867.

Nogueira, E. M., P. M. Fearnside, B. W. Nelson, and M. B. Franca. 2007. Wood density in forests of Brazil's 'arc of deforestation': Implications for biomass and flux of carbon from land-use change in Amazonia. Forest Ecology and Management 248:119-135. 
Nogueira, E. M., B. W. Nelson, and P. A. Fearnside. 2006 Volume and biomass of trees in central Amazonia: influence of irregularly shaped and hollow trunks. Forest Ecology and Management 227:14-21.

Nogueira, E. M., B. W. Nelson, P. M. Fearnside, M. B. Franca, and A. C. A. de Oliveira. 2008b. Tree height in Brazil's 'arc of deforestation': Shorter trees in south and southwest Amazonia imply lower biomass. Forest Ecology and Management 255:2963-2972.

Oliveira, P. J. C., G. P. Asner, D. E. Knapp, A. Almeyda, R. Galvan-Gildemeister, S. Keene, R. F. Raybin, and R. C. Smith. 2007. Land-use allocation protects the Peruvian Amazon. Science 317:1233-1236.

Olson, D. M., et al. 2001. Terrestrial ecoregions of the worlds: A new map of life on Earth. Bioscience 51:933-938.

Overman, J. P. M., H. J. L. Witte, and J. G. Saldarriaga. 1994. Evaluation of regression-models for aboveground biomass determination of Amazon rain-forest. Journal of Tropical Ecology 10:207-218.

Pan, Y. D., et al. 2011. A large and persistent carbon sink in the world's forests. Science 333:988-993.

Pearson, T., S. Walker, and S. Brown. 2005. Sourcebook for land use, land-use change and forestry projects. Winrock International and World Bank BioCarbon Fund, Arlington, Virginia, USA.

Phillips, O., T. R. Baker, T. R. Feldpausch, and R. Brienen. 2009. RAINFOR field manual for plot establishment and remeasurement. Moore Foundation, Leeds, UK.

Pilli, R., T. Anfodillo, and M. Carrer. 2006. Towards a functional and simplified allometry for estimating forest biomass. Forest Ecology and Management 237:583-593.

Poorter, L., and F. Bongers. 2006. Leaf traits are good predictors of plant performance across 53 rain forest species. Ecology 87:1733-1743.

Poorter, L., L. Bongers, and F. Bongers. 2006. Architecture of 54 moist-forest tree species: traits, trade-offs, and functional groups. Ecology 87:1289-1301.

Poorter, L., F. Bongers, F. J. Sterck, and H. Woll. 2003. Architecture of 53 rain forest tree species differing in adult stature and shade tolerance. Ecology 84:602-608.

Quesada, C. A., et al. 2012. Basin-wide variations in Amazon forest structure and function are mediated by both soils and climate. Biogeosciences 9:2203-2246.

R Core Development Team. 2013. R: a language and environment for statistical computing. R Foundation for Statistical Computing, Vienna, Austria.

Rendón Thompson, O. R., J. Paavola, J. R. Healey, J. P. G. Jones, T. R. Baker, and J. Torres. 2013. Reducing emissions from deforestation and forest degradation (REDD+): transaction costs of six Peruvian projects. Ecology and Society $18: 17$

Saatchi, S. S., et al. 2011. Benchmark map of forest carbon stocks in tropical regions across three continents. Proceedings of the National Academy of Sciences USA 108:98999904.

Salimon, C. I., F. E. Putz, L. Menezes-Filho, A. Anderson, M. Silveira, I. F. Brown, and L. C. Oliveira. 2011. Estimating state-wide biomass carbon stocks for a REDD plan in Acre, Brazil. Forest Ecology and Management 262:555-560.
Sterck, F. J., and F. Bongers. 1998. Ontogenetic changes in size, allometry, and mechanical design of tropical rain forest trees. American Journal of Botany 85:266-272.

Sterck, F. J., and F. Bongers. 2001. Crown development in tropical rain forest trees: patterns with tree height and light availability. Journal of Ecology 89:1-13.

Sterck, F. J., H. A. Van Gelder, and L. Poorter. 2006. Mechanical branch constraints contribute to life-history variation across tree species in a Bolivian forest. Journal of Ecology 94:1192-1200.

Thomas, R. Q., J. R. Kellner, D. B. Clark, and D. R. Peart. 2013. Low mortality in tall tropical trees. Ecology 94:920 929.

Thomas, S. C. 1996. Asymptotic height as a predictor of growth and allometric characteristics Malaysian rain forest trees. American Journal of Botany 83:556-566.

Vieilledent, G., R. Vaudry, S. F. D. Andriamanohisoa, O. S. Rakotonarivo, H. Z. Randrianasolo, H. N. Razafindrabe, C. B. Rakotoarivony, J. Ebeling, and M. Rasamoelina. 2012. A universal approach to estimate biomass and carbon stock in tropical forests using generic allometric models. Ecological Applications 22:572-583.

West, G. B., J. H. Brown, and B. J. Enquist. 1997. A general model for the origin of allometric scaling laws in biology. Science 276:122-126.

West, G. B., J. H. Brown, and B. J. Enquist. 1999. A general model for the structure and allometry of plant vascular systems. Nature 400:664-667.

Whitmore, T. 1998. An introduction to tropical rain forests. Oxford University Press, Oxford, UK.

Williamson, G. B., and M. C. Wiemann. 2010. Measuring wood specific gravity ... correctly. American Journal of Botany 97:519-524.

Xiao, X., E. P. White, M. B. Hooten, and S. L. Durham. 2011. On the use of log-transformation vs. nonlinear regression for analyzing biological power laws. Ecology 92:1887-1894.

Zanne, A. E., G. Lopez-Gonzalez, D. A. Coomes, J. Ilic, S. Jansen, S. L. Lewis, R. B. Miller, N. G. Swenson, M. C. Wiemann, and J. Chave. 2009. Data from: Towards a worldwide wood economics spectrum. Dryad Digital Repository. http://dx.doi.org/10.5061/dryad.234

Zhou, J., C. Proisy, X. Descombes, I. Hedhli, N. Barbier, J. Zerubia, J. P. Gastellu-Etchegorry, and P. Couteron. 2010. Tree crown detection in high resolution optical and LiDAR images of tropical forest. Proceedings of the International Society for Optics and Photonics (SPIE) 7824, Remote Sensing for Agriculture, Ecosystems, and Hydrology XII:78240Q. http://dx.doi.org/10.1117/12.865068

Zianis, D. 2008. Predicting mean aboveground forest biomass and its associated variance. Forest Ecology and Management 256:1400-1407.

Zianis, D., and M. Mencuccini. 2004. On simplifying allometric analyses of forest biomass. Forest Ecology and Management 187:311-332.

Zimmerman, J. K., E. M. E. Iii, R. B. Waide, D. J. Lodge, C. M. Taylor, and N. V. L. Brokaw. 1994. Responses of tree species to hurricane winds in subtropical wet forest in Puerto Rico: implications for tropical tree life histories. Journal of Ecology 82:911-922.

\section{Supplemental Material}

\section{Appendix}

Moisture content and wood density of species sampled in this study (Ecological Archives A024-040-A1). 